\title{
Hierarchically Nanoporous Zeolites and Their Heterogeneous Catalysis: Current Status and Future Perspectives
}

\author{
Kyungsu Na - Gabor A. Somorjai
}

Received: 3 October 2014/ Accepted: 24 October 2014/Published online: 23 November 2014

(c) Springer Science+Business Media New York 2014

\begin{abstract}
The research field of hierarchically nanoporous zeolites has been growing at an enormous pace over the past decades. Hierarchically nanoporous zeolites have versatile structural properties such as high surface area and large pore volume that can alleviate diffusional limitations of conventional zeolites with solely microporous framework. In this review, various synthesis strategies to hierarchically nanoporous zeolites and their structural advantages in catalytic reactions will be reviewed. In the first part, many novel synthetic approaches for hierarchically nanoporous zeolites such as post-demetallation, softtemplating, hard-templating, and dual-pore-generating surfactant-directed methods will be introduced. In the second part, catalytic applications of hierarchically nanoporous zeolites on various chemical reactions involving isomerization, cracking, alkylation and oxidation will be discussed. The present comprehensive review will provide future opportunities and perspectives on the research of hierarchically nanoporous zeolites including their applications to catalytic reactions.
\end{abstract}

Keywords Zeolites - Heterogeneous catalysis · Mesoporous materials $\cdot$ Nanoparticles $\cdot$ Acid catalysis

\footnotetext{
K. Na · G. A. Somorjai ( $₫)$

Department of Chemistry, University of California-Berkeley,

Berkeley, CA 94720, USA

e-mail: Somorjai@berkeley.edu

K. Na · G. A. Somorjai

Chemical Sciences Divisions, Lawrence Berkeley National

Laboratory, Berkeley, CA 94720, USA
}

\section{Introduction to Zeolites and Their Catalysis}

Zeolite materials are an important class of crystalline aluminosilicate minerals with microporous structures of usually below $1 \mathrm{~nm}$ in diameter [1]. The micropores in the zeolite crystal are very uniform in size and shape, which can discriminate molecules depending on their size and shape. Accordingly, zeolites have proved their important values in molecular size/shape-selective adsorption, separation processes, and more broadly speaking, in any field related with host-guest chemistry. The crystalline framework of zeolite is also noteworthy, which imparts zeolites with very high thermal, hydrothermal, and mechanical stabilities. These are very important properties that allow zeolite to be used in many catalytic processes under harsh reaction conditions.

The zeolite framework consists of ordered networks of $\mathrm{SiO}_{4}$ and $\mathrm{AlO}_{4}$ tetrahedra that are interconnected by covalent bonding through oxygen bridges. The presence of $\mathrm{Al}$ in the silicon oxide framework as the heteroatom makes the zeolite framework negatively charged, which required one cation charge compensator per one $\mathrm{Al}$ atom. Usually the cation can be alkali metal cation such as $\mathrm{Na}^{+}$and $\mathrm{K}^{+}$, but they are easily exchangeable to other cations. In particular, when $\mathrm{H}^{+}$is substituted, the $\mathrm{H}^{+}$site can behave as strong Brönsted acid that can also be converted to Lewis acid sites through dehydroxylation. Depending on the framework type, $\mathrm{Si} / \mathrm{Al}$ ratio and synthesis condition, the Brönsted/Lewis acid site ratio can be varied over a wide range. Accompanied with the size/ shape selective host-guest chemistry, such framework acidity allows zeolites to be used as very valuable heterogeneous catalyst that can convert raw-chemicals to the value-added products, giving the biggest impact on the industry [2-4]. 
The high surface area and large pore volume due to the microporous framework gives an opportunity for being a supporting material that can incorporate metal nanoclusters inside the micropore cavity. The metal nanoclusters incorporated zeolites possess acid catalytic activity as well as special catalytic function of metal nanoclusters such as hydrogenation/dehydrogenation. Bigger metal nanoparticles can also be supported at the external surface of zeolite crystal, but the external surface area of zeolite is almost negligible as compared to the internal surface area of micropores inside the zeolite framework. Accordingly, supporting bigger metal nanoparticles at the external surface area with high loading is limited. More seriously, the supported metal nanoparticles can sinter to make much larger nanoparticles more easily than the metal nanoclusters stabilized inside the micropore cavity as confined, which can deactivate the catalytic activity of metal nanoparticles quickly.

Generally, conventional zeolites are the solely microporous material with big crystal size usually in a micrometer scale. The long-range order of micropores in the zeolite crystal can provide the well-known size/shape selective molecular discrimination during adsorption/ separation or catalytic reaction [5, 6]. However, such bulky crystalline system can suffer from the diffusion limitation [7, 8]. It causes a slow mass transport to and away from the catalytic sites inside the micropores, which can increase the possibility of secondary or undesired side reactions. In addition, bulky molecules with sizes larger than the micropore aperture are excluded from entering the zeolite framework. Although the catalytic sites exist at the external surface as well, their density is extremely small as compared to the total number of catalytic sites over the zeolite framework, and hence the catalytic activity toward bulky molecules is very weak. Due to these steric and diffusional limitations, it is highly desirable to increase the extent of zeolite surface that are efficiently accessible to various sized molecules. In addition, reduction of the zeolite crystal size to nanocrystal having a few tens of nanometers or less than that is highly encouraged in the synthesis of zeolites.

In this review article, enormous studies for the synthesis of hierarchically nanoporous zeolites and their catalytic effects on various chemical reactions will be discussed (Scheme 1). The term of "hierarchically nanoporous zeolites" means the zeolite materials having hierarchically nanoporous structures having two or multiple pore length scales. Since the zeolite has micropores $(0-2 \mathrm{~nm}$ in diameter) intrinsically, zeolite structure should have another pore in a different length scale such as mesopore $(2-50 \mathrm{~nm}$ in diameter) or macropore ( $>50 \mathrm{~nm}$ in diameter) for being defined as hierarchically nanoporous zeolites.
Accompanying with the zeolite intrinsic micropores, dualor tri-hierarchically nanoporous zeolites can be synthesized through various synthesis pathways that will be summarized in the first part of this review. The hierarchically nanoporous zeolites are also called as hierarchical zeolites in short, and often called as mesoporous zeolites when the secondary pores are in a mesopore scale. In the second part of this review, the contribution of hierarchical zeolites on the catalytic reactions as the heterogeneous catalyst will be discussed according to type of the reaction. For convenience, abbreviations and their full names used in this review are summarized in Table 1.

\section{General Synthesis of Conventional Zeolites and Their Characterizations}

One of the important advances in the synthesis of zeolites is the use of alkylammonium cations as the molecular template that can generate the micropores $[1,9,10]$. In 1961, Barrer et al. reported a synthesis of zeolite with tetramethylammonium (TMA) cations that can increase the framework $\mathrm{Si} / \mathrm{Al}$ ratio in the aluminosilicate zeolite framework [11]. The use of organic template is very helpful for generation of ordered arrangement of micropores inside the crystal. Thermodynamically, formation of ordered pore arrangement in the single solid such as zeolite crystal is unfavorable process. Furthermore, as the size of pore becomes smaller, the pore formation becomes thermodynamically much more unfavorable due to the increase of surface free energy of the porous solid having high surface area. Such high potential energy can be compensated by the aid of organic molecular template, also namely as micropore structure-directing agent (SDA).

The use of micropore SDA in the zeolite synthesis was exceedingly spread out to many new synthetic zeolites especially in the high $\mathrm{Si} / \mathrm{Al}$ ratio (usually $\mathrm{Si} / \mathrm{Al}>10$ ). Many new synthetic zeolites currently used in the industry could be crystallized using molecular micropore SDA with various structures prepared by organic synthesis route. For example, zeolite BEA, MFI and MEL could be synthesized at $100-200{ }^{\circ} \mathrm{C}$ using tetraethylammonium (TEA), tetrapropylammonium (TPA) and tetrabutylammonium (TBA) ions, respectively. The synthesis pHs are generally larger than 10 , where the synthesis solution contains alkali-metal ions as well as the other zeolite synthesis sources such as silica and alumina precursors. After the zeolite crystallization, the zeolite containing micropore SDA was calcined at $\sim 500{ }^{\circ} \mathrm{C}$ for removal of organic molecular SDAs. As well as the aluminosilicate form of zeolite, aluminophosphate form of zeo-type materials can be synthesized by differing the synthesis condition to acidic or mildly basic conditions usually without alkali-metal cations [12]. In a 
Scheme 1 Synthesis of hierarchical zeolites and their catalytic advantages

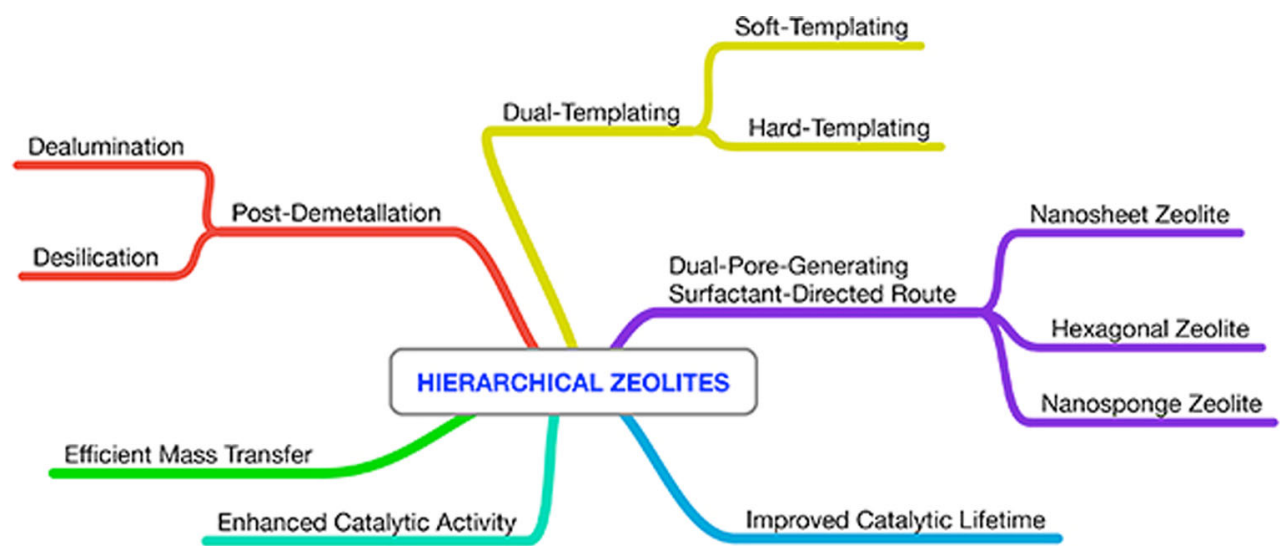

Table 1 Abbreviations and full names used in this review

\begin{tabular}{ll}
\hline TMA & Tetramethylammonium \\
SDA & Structure-directing agent \\
TEA & Tetraethylammonium \\
TPA & Tetrapropylammonium \\
TBA & Tetrabutylammonium \\
USY & Ultra-stable Y \\
FCC & Fluid catalytic cracking \\
TEM & Transmission electron micrograph \\
CTABr & Cetyltrimethylammonium bromide \\
TPABr & Tetrapropylammonium bromide \\
3DOM & 3-Dimensionally ordered mesoporous \\
CMK & Carbon mesostructured by KAIST \\
XRD & X-ray diffraction \\
TPHAC & 3-(Trimethoxysilyl)propyl \\
& hexadecyldimethylammonium chloride \\
TEOS & Tetraethyoxyorthosilicate \\
BET & Brunauer-Emmett-Teller \\
HETCOR NMR & Heteronuclear correlation nuclear \\
TPD & magnetic resonance \\
\hline & Temperature-programmed desorption \\
\hline &
\end{tabular}

typical synthesis condition for aluminophosphate, alumina precursor, $\mathrm{H}_{3} \mathrm{PO}_{4}$ and micropore $\mathrm{SDA}$ were mixed in water, and hydrothermally heated at $100-200{ }^{\circ} \mathrm{C}$.

\section{Development of Synthesis Strategies for Hierarchically Nanoporous Zeolites}

\subsection{Post-Synthetic Demetallation of Zeolite Crystals}

Large pores in meso- or macropore scales can be generated within the zeolite crystal via post-synthetic treatments involving chemical or hydrothermal routes [13-15]. This post-synthetic route can be diversified into dealumination or desilication depending on the demetallated species such

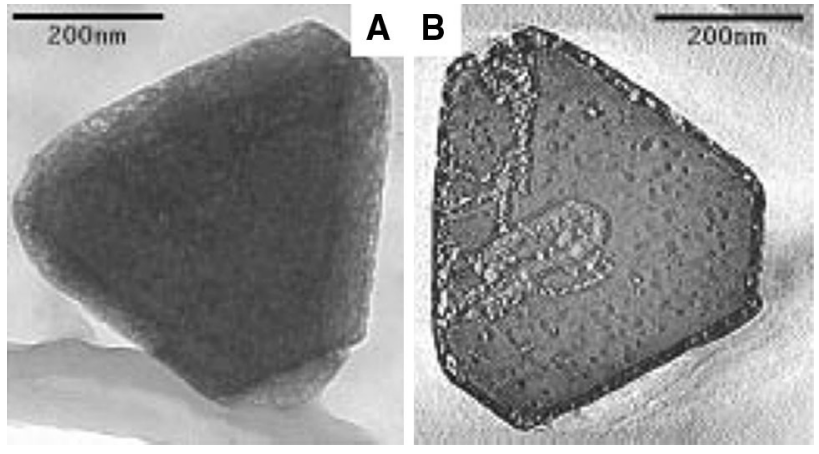

Fig. 1 a 2D-TEM image of a single crystal of USY zeolite and $\mathbf{b}$ a thin $(1.7 \mathrm{~nm})$ slice through the 3D-TEM reconstruction of this crystal. Reprinted with permission from Ref. [18]. Copyright 2001 WileyVCH Verlag GmbH \& Co. KGaA, Weinheim

as $\mathrm{Al}$ or $\mathrm{Si}$, respectively. In an old strategy, $\mathrm{Al}$ species can be leached out from the zeolite framework by steaming with water vapor at $500{ }^{\circ} \mathrm{C}$ and subsequent washing with liquid acid, where mesopores are formed [16, 17]. This is well known procedure for preparation of ultra-stable $\mathrm{Y}$ (USY) zeolites that can be used in fluid catalytic cracking (FCC) reaction [7]. In a steam-dealumination process, the $\mathrm{NH}_{4}{ }^{+}$-form of $\mathrm{Y}$ zeolite was steamed at $500{ }^{\circ} \mathrm{C}$, and subsequently treated with acid washing to remove the extraframework $\mathrm{Al}$ species. This approach is useful for high- $\mathrm{Al}$ zeolites with the usual Si/Al ratios less than 10. Selective extraction of $\mathrm{Al}$ species without destroying crystallinity is ideal, but the dealumination process induces an unintended local destruction of crystal structure. The space where the $\mathrm{Al}$ species was leached out is mesoporous channels (mostly $5-100 \mathrm{~nm}$ in diameter) as a defect region inside the zeolite crystal (Fig. 1). Recently, 3D-transmission electron micrograph (TEM) tomography in combination with $\mathrm{N}_{2}$ adsorption and mercury porosimetry demonstrated that a significant fraction of mesopores exists as isolated cavities inside the zeolite crystal $[18,19]$.

In order to retain the crystal structure of dealuminated zeolite crystal, the post dealumination can also be carried 
Fig. 2 Schematic representation of the influence of $\mathrm{Al}$ content on the desilication treatment of MFI zeolites in $\mathrm{NaOH}$ solution and associated mechanism of pore formation. Reprinted with permission from Ref. [30]. Copyright 2004 American Chemical Society

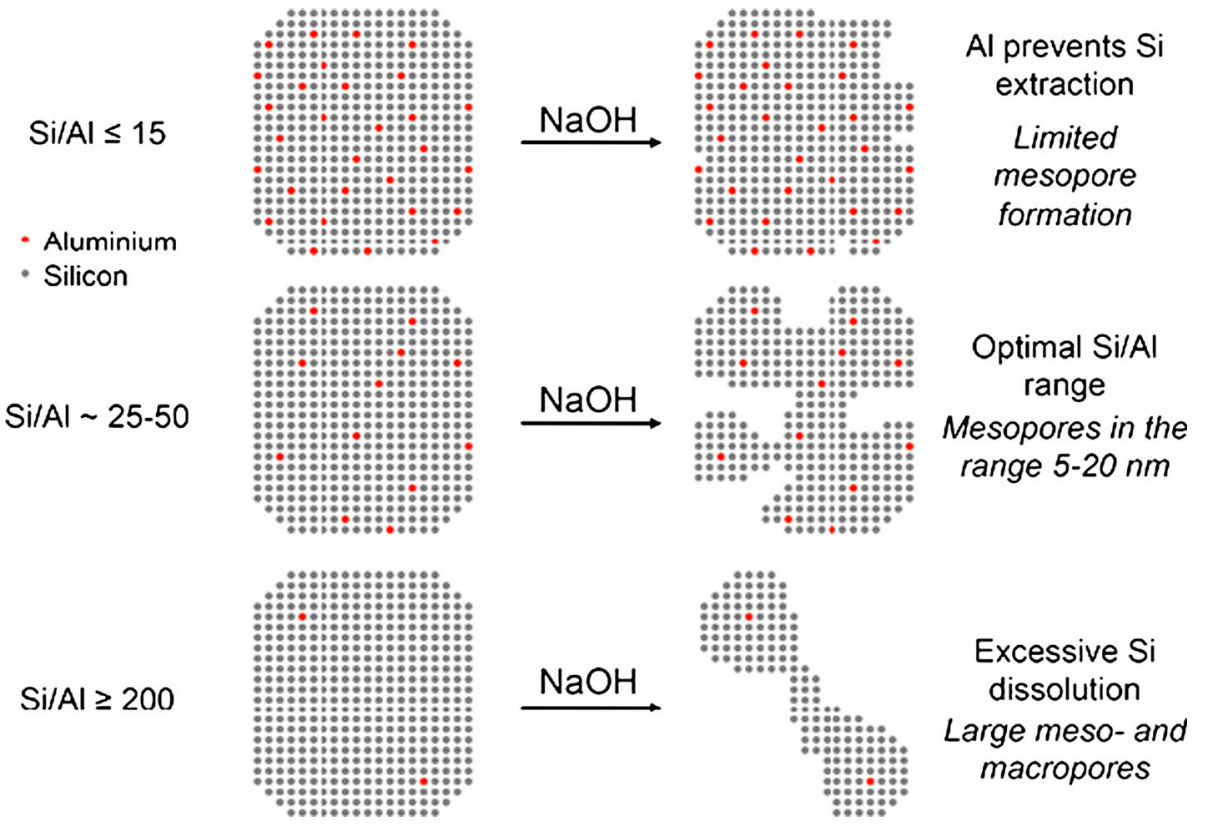

out in aqueous solutions containing ammonium hexafluorosilicate [20, 21] and $\mathrm{SiCl}_{4}$ [22-24]. This can heal the dealuminated framework sites with silicate species during the dealumination treatment. The resultant pore textural properties and $\mathrm{Al}$ distribution depend very much on the types of dealumination procedure [21]. The dealumination process involves an inevitable change of acid property, which is generally difficult to control intentionally. Since the mesopores are generated by the extraction of framework Al that was responsible for zeolite acidity, the dealumination reduces the total number of acid sites.

Contrary to the dealumination, mesopores can also be generated by post-desilication method [14, 25]. In this route, the mesopores can be produced by base treatment that can leach out the $\mathrm{Si}$ species from the zeolite framework, which makes mesopores that are interconnected each other and accessible from the external surface of the zeolite crystal [26, 27]. The desilication process is effective for high-silica zeolites (usually $\mathrm{Si} / \mathrm{Al}>20$ ) than high $\mathrm{Al}$ zeolites [28, 29]. It was reported that mesoporous textures generated by the desilication process strongly depend on the concentration and distribution of $\mathrm{Al}$ within the zeolite crystals [26, 28, 30]. Silica-rich domains are easily leached out to generate large mesopores while Al-rich domains remain relatively intact. In 1992, Dessau et al. reported the selective extraction of framework Si from large MFI zeolite crystal in an attempt to identify Al gradients of desilicated MFI zeolite. They observed that the interior of the zeolite was mostly dissolved, which is due to the high concentration of $\mathrm{Al}$ at the exterior surface of the crystals [26, 28].
The effect of $\mathrm{Si} / \mathrm{Al}$ ratio according to the desilication by base-treatment has been profoundly investigated (Fig. 2) [30]. The result proved that the frameworks of MFI zeolite having high $\mathrm{Al}$ content with $\mathrm{Si} / \mathrm{Al}<20$ made local desilication difficult, because the framework was insoluble under mild basic conditions. The concentration of liquid base is very important because the zeolite framework was totally destroyed under strong basic conditions. In contrast, highly siliceous zeolites having low $\mathrm{Al}$ content with $\mathrm{Si} / \mathrm{Al}>50$ showed excessive and unselective dissolution, giving rise to the generation of too large pores. From this study, it was demonstrated that the $\mathrm{Si} / \mathrm{Al}$ ratios of $25-50$ in the pristine zeolite framework were optimum for the development of uniform mesoporosity maintaining the MFI crystal morphology [30].

As another post-demetallation route, both dealumination and desilication treatments can be applied in a sequential manner. Zeolite $\mathrm{Y}$ was tested for this sequential posttreatment and the result showed that two different scales of mesopores in addition to the intrinsic zeolite micropores were obtained [31]. The smaller sponge-like mesopores ( $\sim 3 \mathrm{~nm}$ in diameter) resulted from desilication while the larger mesopores $(\sim 27 \mathrm{~nm})$ were generated due to steaming and acid leaching of framework Al species.

The post-synthetic demetallation often produces very random large pores in a wide pore size distribution. Although it is recently developed to make uniform size of mesopores by desilication in the presence of cetyltrimethylammonium bromide (CTABr) surfactant [26, 32], the mesopores generated via post-demetallation are very uncontrollable and undesirably formed. However, the post-demetallation route 


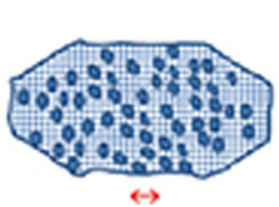

$12,18 \mathrm{~nm}$

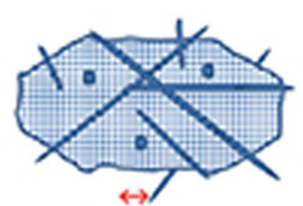

$12 \mathrm{~nm}$

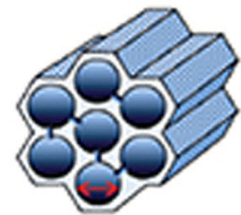

$10 \mathrm{~nm}$

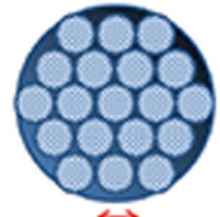

$10-40 \mathrm{~nm}$
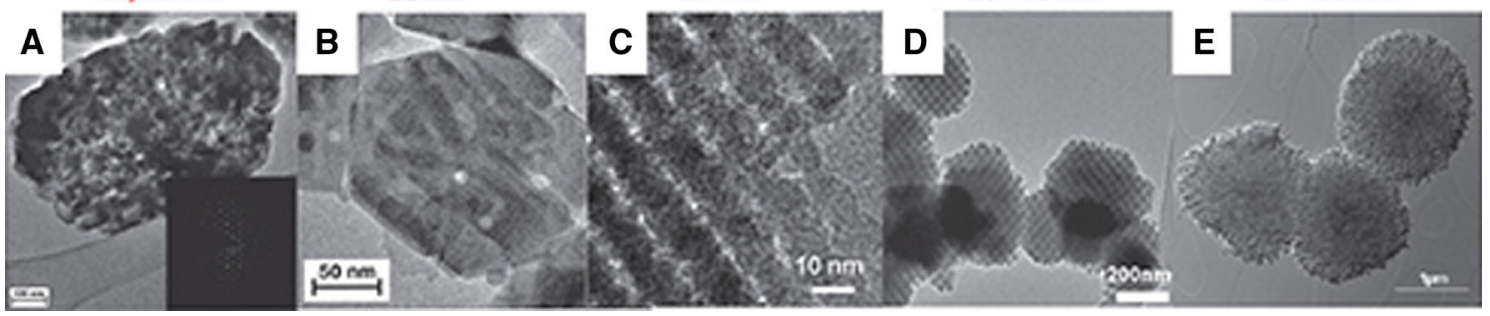

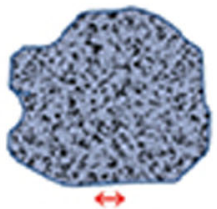

$10 \cdot 20 \mathrm{~nm}$
Fig. 3 Overview of carbon-based hard-templating routes for hierarchical zeolites. Top graphical representations of zeolite-carbon composites, bottom electron micrographs of final hierarchical zeolite materials. a MFI zeolite single crystal synthesized with 12 or $18 \mathrm{~nm}$ carbon nanobeads, b silicalite-1 single crystal synthesized with $12 \mathrm{~nm}$ wide, micron-sized carbon nanotubes, $\mathbf{c}$ ordered mesoporous

is advantageous in that it can make the hierarchically nanoporous structure in zeolite crystal very economically with mass production.

\subsection{Addition of Two Different SDAs}

Molecular-templating synthesis strategy for various porous materials including zeolite and mesoporous silica is very convenient and efficient method for making molecularlength scale pores in a regular arrangement. For example, the microporous framework of zeolites can be efficiently generated by the aid of molecular template such as amine or ammonium molecules that can attract aluminosilicate anions via electrostatic interaction. Similarly, the mesopores of mesoporous silica materials can be generated by micelle formed by self-assembly of surfactant molecules. Combining these two molecular-templating strategies, larger pores may be generated in the zeolite structure [33-35]. In a typical strategy, both micropore and mesopore phases can be generated in the zeolites hierarchically by simply mixing two appropriate templates: i.e., tetrapropylammonium bromide (TPABr) for micropore generation and $\mathrm{CTABr}$ surfactant for mesopore generation. These two templates should work cooperatively for making the hierarchically nanoporous structures in the single zeolite crystal. In general, such dual-templating synthesis route can be divided into hard- and soft-templating route according to the physical and chemical characteristics of large-pore generating agent. The hard templates are usually in the solid phases such as carbon nanobead, carbon nanotube, polymer bead, etc., whereas the soft templates are typically constituted of organic molecular systems of surfactant micelles or polymers. silicalite-1 synthesized with KIT-6 silica replicated CMK-L carbon, d 3DOM BEA zeolite synthesized with 3DOM carbon replicas, e hierarchical MFI zeolite synthesized with pyrolyzed sugar/silica composites. Reprinted with permission from Ref. [15]. Copyright 2013 Royal Society of Chemistry

\subsubsection{Hard-Templating Route}

The hard-templating route uses the solid nanostructures as the meso- or macropore SDA during the crystallization process of zeolite crystal (Fig. 3) [36-59]. The zeolite synthesis gels containing the micropore SDA are crystallized with inclusion of hard-templates such as carbon nanobead, carbon nanotube and polymer bead. In general crystallization process, the zeolite was gelated within the interstitial voids that are made by hard-templates. After the zeolite crystallization, the hard-templates were removed by calcination at $500{ }^{\circ} \mathrm{C}$, which imprinted meso- or macropores within the zeolite crystals depending on the diameter of hard-templates. In this approach, the zeolite synthesis solution should be a concentrated precursor gel that can be crystallized at the confined spaces made by closed-assembly of hard-templates. Otherwise, zeolite precursors were exhausted from the homogeneous mixture of zeolite gel and hard-templates, which made the separated formation of normal zeolite crystal without incorporating the hardtemplates. In a successful case, open mesopores can be generated within microporous zeolite crystal, where the mesoporous structure generally corresponds to the inverse replica of the hard-templates.

Carbon-based nanotemplates such as carbon nanoparticles, carbon nanotubes, and carbon aerogels have been used as the most representative hard-templates. Jacobsen et al. synthesized MFI zeolite single crystals having intracrystalline mesopores with uniform pore size and large mesopore volume exceeding $1.0 \mathrm{~cm}^{3} \mathrm{~g}^{-1}$, using carbon nanoparticles as hard templates [36]. The multi-walled carbon nanotubes [37, 38], carbon nanofibers [39] and carbonized sucrose $[40,41]$ were also used as the 

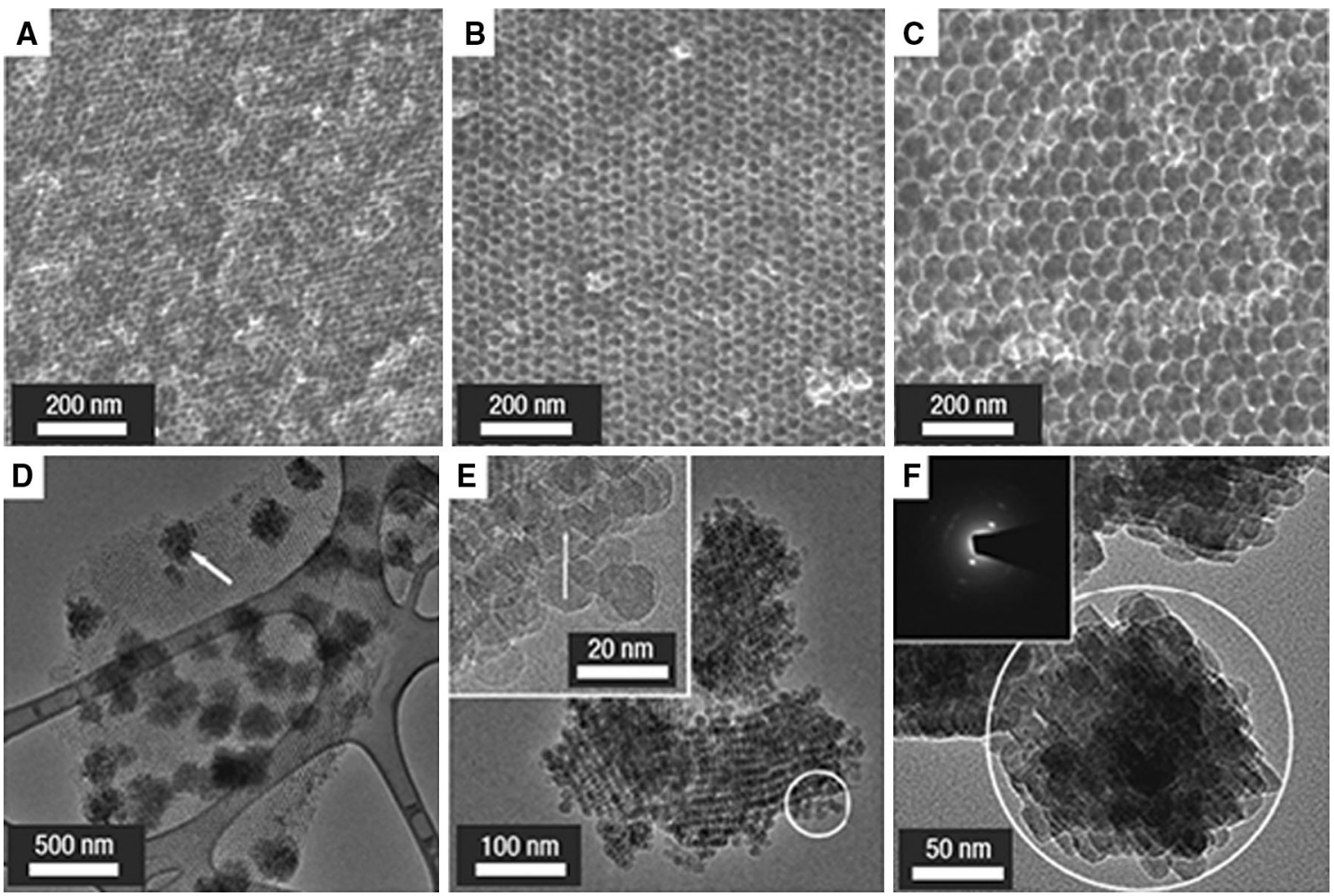

Fig. 4 SEM images of empty 3DOM carbon replicas formed from colloidal silica with the size of a $10 \mathrm{~nm}, \mathbf{b} 20 \mathrm{~nm}$ and c $40 \mathrm{~nm}$. TEM images of 3DOM-imprinted silicalite-1 crystals, which shows isolated crystalline domains (arrow in d) dispersed throughout the 3DOM carbon template, and $(\mathbf{e}, \mathbf{f})$ representative particulate domains after the 3DOM carbon template was removed. Reprinted with permission from Ref. [57]. Copyright 2008 Macmillan Publishers Limited

produced macroporous structures $(250 \mathrm{~nm}$ in diameter) reflecting the bead size in a macro scale in the zeolite framework [58].

The CMK-n-type ordered mesoporous carbons could be used as a template if the mesopores of CMK carbons are sufficiently large ( $\sim 10 \mathrm{~nm}$ or more). Sakthivel et al. [52] and Yang et al. [53] demonstrated that the hierarchical zeolites could be synthesized by using CMK-1 (cubic structure) and CMK-3 (2D-hexagonal structure) [54-56]. The zeolites contained uniform mesopores with the large pore volumes of $0.8-0.9 \mathrm{~cm}^{3} \mathrm{~g}^{-1}$. The zeolites exhibited an $\mathrm{X}$-ray diffraction (XRD) peak at low angle, indicating that the mesopores are regularly oriented. In more recent years, it was reported that the humidity during the dry-gel synthesis, pore diameters of mesoporous carbon templates and their framework rigidity are playing a crucial role for the successful synthesis of mesoporous zeolite with mesoporous carbon templates [59].

\subsubsection{Soft-Templating Route}

Another important dual-templating synthesis strategy is soft-templating route, where the soft-templates are organicbased molecules that are usually larger than the size of 
Fig. 5 Molecular structure of organosilane surfactant (a). Schematic representation of crystallization process of mesoporous zeolite using organosilane surfactant as a mesopore structure-directing agent (bottom). Reprinted with permission from Ref. [67]. Copyright 2006 Macmillan Publishers Limited
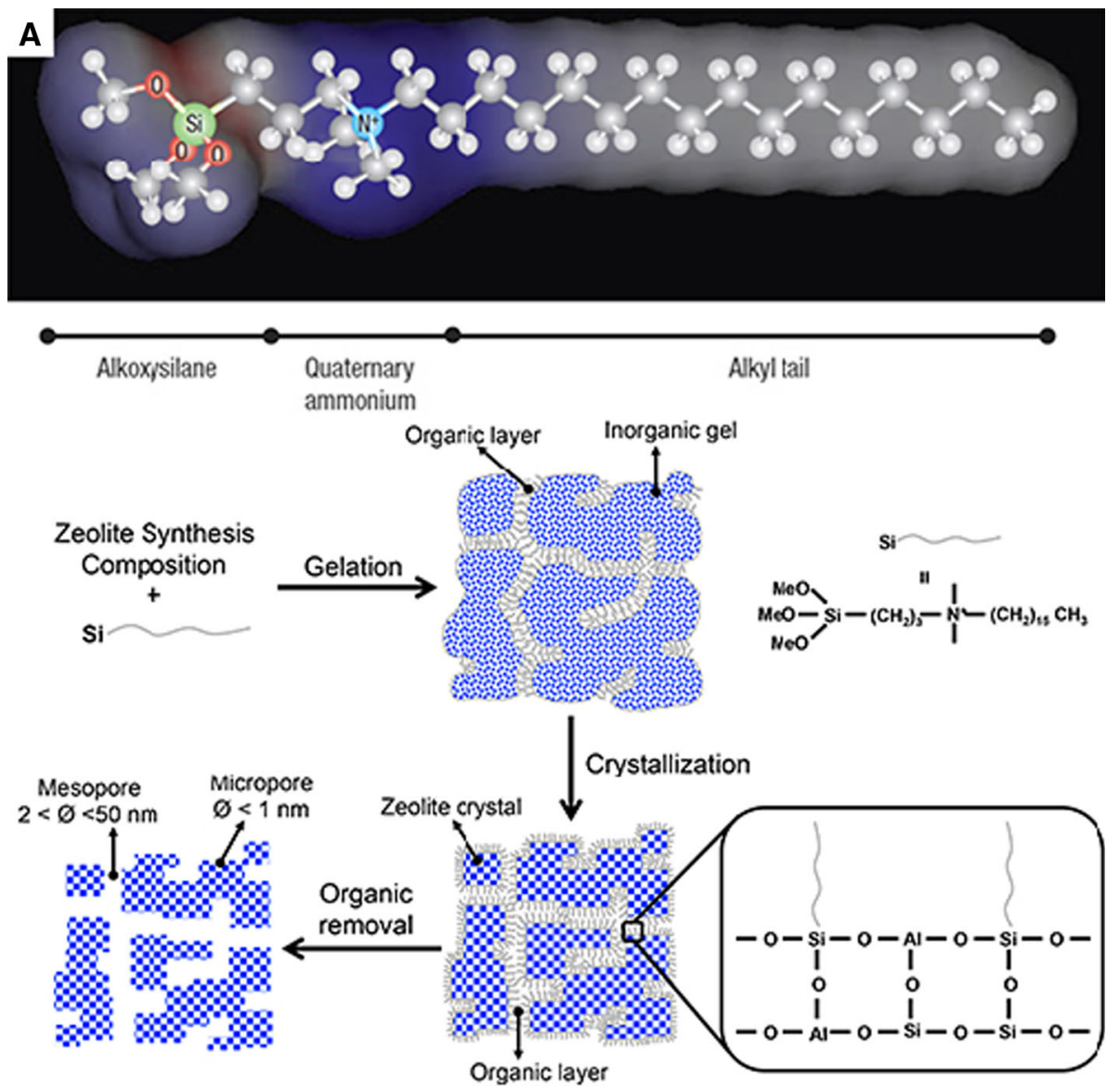

conventional micropore SDA such as TPABr. The earliest attempt of soft-templating approach in the synthesis of zeolite was reported with co-addition of quaternary ammonium surfactant such as CTABr with conventional micropore SDA such as TPABr in the zeolite synthesis solution [60]. The expected performance of these two SDAs was to generate both mesoporous and microporous structure within zeolite crystal through cooperative structure-directing actions of two individual SDAs. However, the results were opposite. The two individual SDAs played each role competitively: depending on the hydrothermal time and temperature, the product was obtained as a solely mesoporous material with an amorphous framework, a solely crystalline microporous zeolite, or their physical mixture.

After then, multi-step synthesis strategies for assembling preformed zeolite seeds into a mesoporous structure were proposed in order to prevent the separate formation of zeolite and mesoporous silica [61-64]. In a modified method, Naik et al. performed steam-assisted crystallization (i.e., dry-gel synthesis) of zeolite seeds that were preassembled by surfactants [65]. However, the resultant material was still a physical mixture of bulk zeolite crystals and amorphous mesoporous materials.

Choi et al. have developed a synthesis method using an organosilane surfactant as a mesopore-directing agent $[66,67]$. The organosilane surfactant has a hydrolysable methoxysilyl moiety connected to a hydrophilic quaternary ammonium and a hydrophobic alkyl tail, which can be exemplified as 3-(trimethoxysilyl)propyl hexadecyldimethylammonium chloride $\left(\left[\left(\mathrm{CH}_{3} \mathrm{O}\right)_{3} \mathrm{SiC}_{3} \mathrm{H}_{6}-\right.\right.$ $\left.\mathrm{N}^{+}\left(\mathrm{CH}_{3}\right)_{2} \mathrm{C}_{16} \mathrm{H}_{33}\right] \mathrm{Cl}$, 'TPHAC' in short) (Fig. 5a) [67, 68]. The TPHAC surfactant was added into a composition for MFI zeolite synthesis, which contained TPABr as the micropore SDA and sodium silicate (or TEOS) as the silica source. Unlike the CTABr surfactant, the TPHAC surfactant micelles were well participated into the crystallization of silica source to the zeolite framework due to the silica moiety in TPHAC that can act as the source of silica (Fig. 5). The resultant zeolites possessed a large volume of mesopores with uniform pore diameters that could be controlled systematically according to the tail length of the organosilane surfactant, and/or by increasing the synthesis temperature. In 


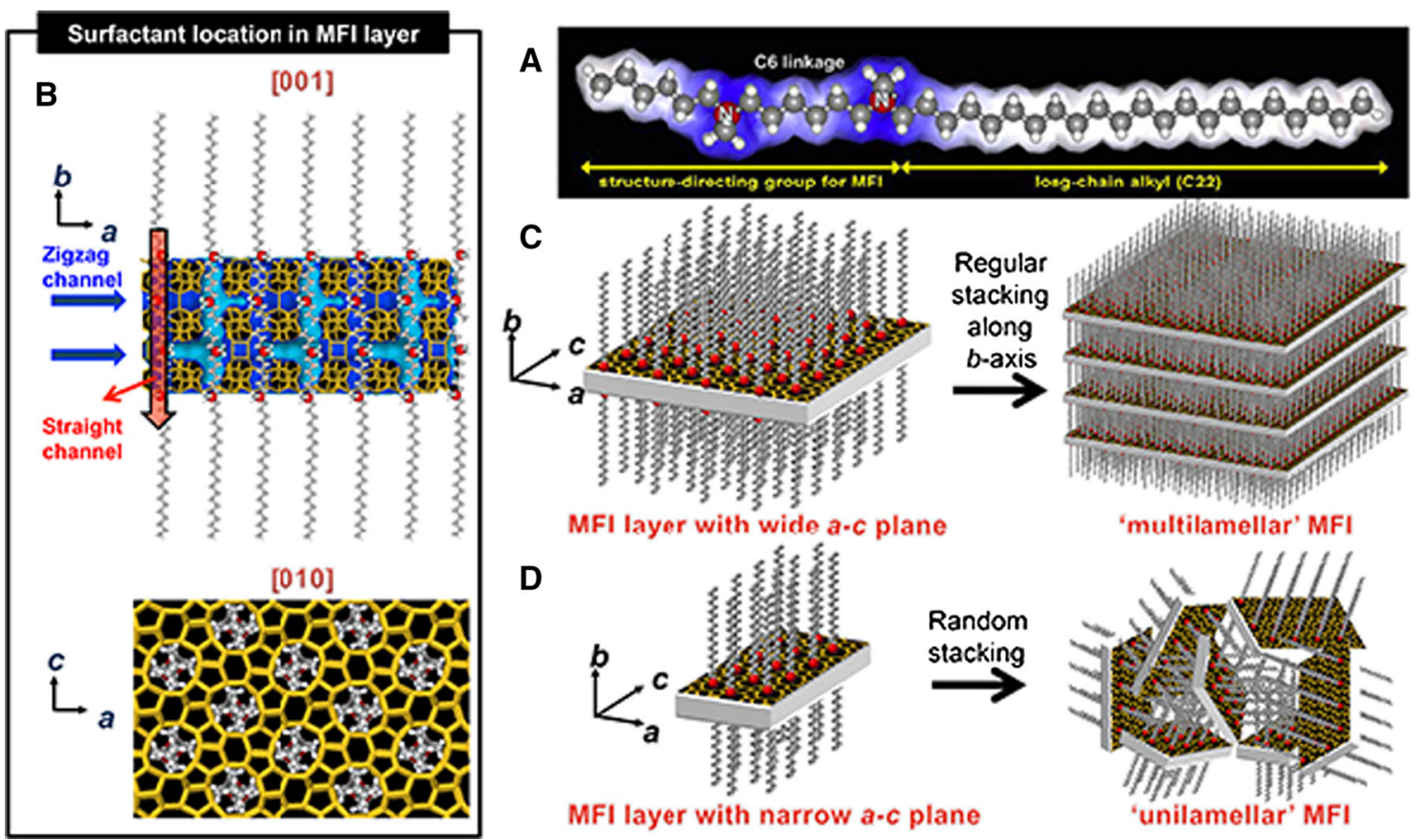

Fig. 6 a Molecular structure of $\mathrm{C}_{22^{-6} 6^{-6}}$ surfactant. b Proposed structure model for the single MFI nanosheet, where the surfactants are aligned along the straight channel of MFI framework, and diquaternary ammonium head groups are embedded inside the zeolite

addition, the organosilane-directed synthesis strategy was extended to other zeolites including aluminophosphate [69], silicoaluminophosphate [70], and even basic zeolites having SOD structure [71].

\subsection{Dual-Pore-Generating Surfactant-Directed Route}

Since the report on MCM-41 in 1992 [72], it has been a dream in zeolite research field to synthesize ordered mesoporous materials where mesopore walls are composed of zeolitic crystalline microporous framework. As aforementioned, many synthesis strategies have been developed for recent decades. However, the new synthesis strategies introduced above are post-treatment methods or indirect synthesis routes by the addition of secondary templates in the presence of conventional micropore SDAs. But a dream in the zeolite science and research field was to develop a generalized direct route for hierarchical zeolites having ordered mesopores and micropores arrangements with one single SDA. In principle, a dual-pore-generating surfactant that is covalently joining a zeolite SDA with a hydrophobic alkyl tail can be used for this purpose. However, the actual synthesis has been unsuccessful for quite a long time. In the following sections, the successful achievement on the development of dual-pore-generating surfactant-directed synthesis route to hierarchically nanoporous zeolites will be reviewed. framework. Depending on the synthesis condition, the MFI nanosheet can be regularly assembled into multilamellar mesostructure (c), or randomly stacked into unilamellar (d). Reprinted with permission from Ref. [73]. Copyright 2009 Macmillan Publishers Limited

\subsubsection{Synthesis of Nanosheet Zeolites Using Single Diquaternary-Ammonium Surfactant}

The first success of dual-pore-generating surfactant was reported on the synthesis of ordered lamellar structures where the framework was built with $2 \mathrm{~nm}$ thick MFI zeolite layers [73-75]. The first success was made with the surfactant represented with the formula of $\mathrm{C}_{22} \mathrm{H}_{45}$ $\mathrm{N}^{+}\left(\mathrm{CH}_{3}\right)_{2}-\mathrm{C}_{6} \mathrm{H}_{12}-\mathrm{N}^{+}\left(\mathrm{CH}_{3}\right)_{2}-\mathrm{C}_{6} \mathrm{H}_{13}$ (designated as $\mathrm{C}_{22-6-6}$ hereafter), which consisted of $\mathrm{C}_{22}$-based one long alkyl tail connected by two quaternary ammoniums constituting a hydrophilic head group (Fig. 6a). Remarkably, this $\mathrm{C}_{22-6-6}$ surfactant could generate the nanosheet-type MFI zeolite with only 2-nm thickness in the absence of TPABr. Depending on the concentration of $\mathrm{Na}^{+}$in the synthesis solution, the zeolite nanosheets formed an irregular assembly into an unilamellar or regular stacking into an ordered multilamellar mesostructure wherein the mesopores are formed between the intersheet layers of 2-nm-thick MFI zeolite (Fig. 6).

The multilamellar mesostructure was composed of alternating layers of MFI nanosheets (approximately 2-nm thick) and surfactant lamellae, and hence the interlamellar distance could be systematically controlled according to the surfactant tail lengths [76]. However, it was necessary to do the post-pillaring process for retaining the interlayer mesopore spaces before the surfactant was removed. 
Fig. 7 a Molecular structure of $\mathrm{C}_{18-6-6-18}$ surfactant, b SEM, $\mathbf{c}$, d TEM, and e XRD pattern of hexagonally ordered crystalline mesoporous molecular sieve after surfactant removal. Reprinted with permission from Ref. [83]. Copyright 2011 AAAS
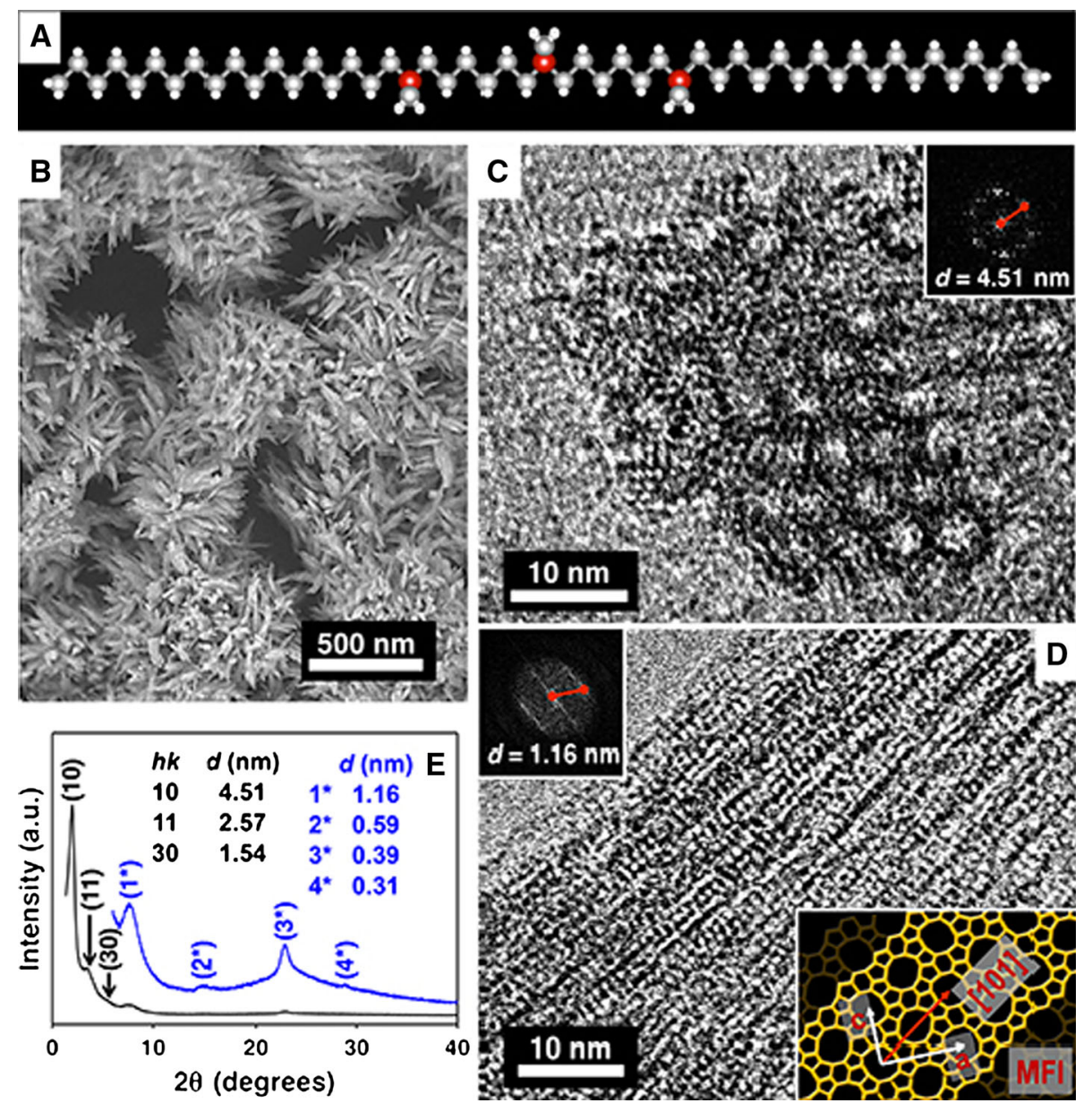

Though the multilamellar structure requires the post-synthetic pillaring process, the pillared MFI nanosheet exhibited much larger amount of external acid sites than conventional MFI zeolite as characterized by FT-IR after the adsorption of pyridine molecule as the organic base probe [76]. In the case of the unilamellar mesostructure, the zeolite nanosheets with very narrow a-c planes supported each other in a random pile. Thus, no mesostructural orders were observed, but the irregularly assembled nanosheet layers could possess very high BET surface area $\left(\sim 700 \mathrm{~m}^{2} \mathrm{~g}^{-1}\right)$ with a large pore volume $\left(\sim 1.2 \mathrm{~cm}^{3} \mathrm{~g}^{-1}\right)$ due to the self-supporting formation. This result was comparable to a random assembly of zeolite nanosheets that was prepared through exfoliation of layered zeolite precursors [77-79].

Intrinsically, the lamellar-type structure often requires post-synthetic treatment such as post-delamination and post-pillaring for retaining the high mesoporosity after calcination. Self-pillared zeolite nanosheets by repetitive branching were synthesized for this purpose where the zeolite nanosheets connected orthogonally each other in an arrangement of house-of-cards [80]. In very recent days, the controlled synthesis for the self-stacking nanosheettype zeolites has been attempted through designing the surfactant-type SDAs [81]. The addition of phenyl or naphthyl groups into the hydrophobic alkyl tail could make single-crystalline mesostructured zeolite nanosheets [81]. It was also controllable that the bolaform amphiphilic surfactant molecules with bi-quaternary ammonium head group and biphenyl groups can produce $90^{\circ}$ rotational boundary, which results in a mesoporous zeolite with high surface area after calcination.

\subsubsection{Generalization of Dual-Pore-Generating Surfactant- Directed Synthesis Route to Other Hierarchically Nanoporous Zeolites or Zeotype Materials}

Since the first success of dual-pore-generating $\mathrm{C}_{22-6-6}$ surfactant-directed synthesis of nanosheet MFI zeolites, various zeolite structures with mesoporous structures were synthesized. The rule-of-thumb on the design of successful dual-pore-generating surfactants was reported [82], which allowed successful synthesis of various mesoporous structures with various zeolite framework structures. A tri- 

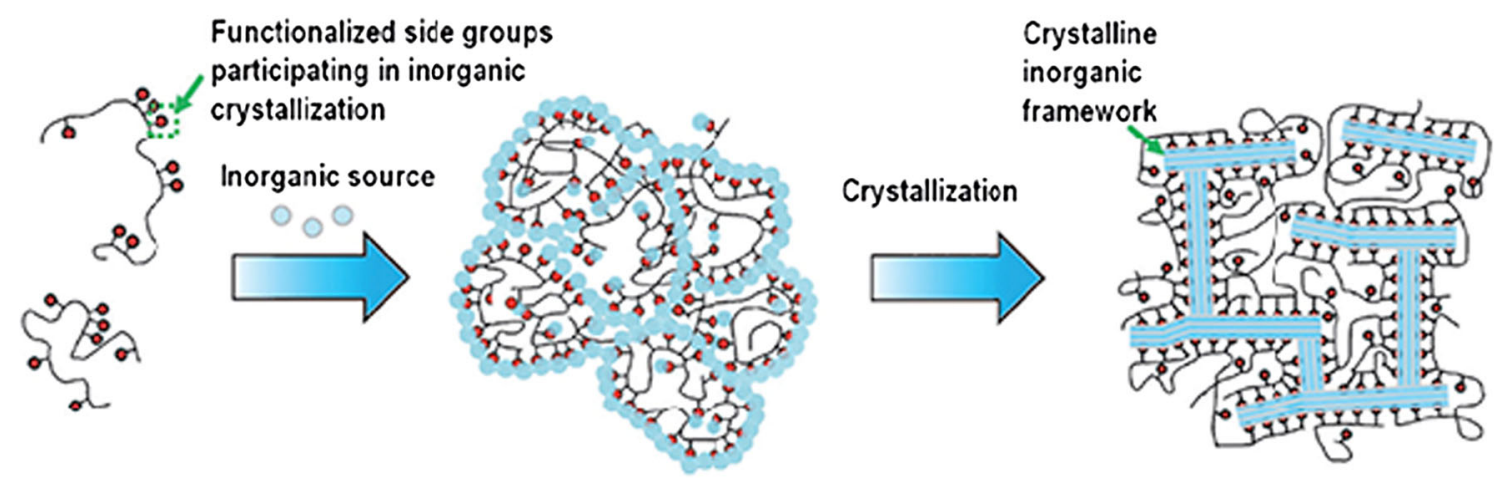

Fig. 8 Schematic drawing of random-graft polymer-directed inorganic crystallization. Amorphous linear polymers are functionalized with inorganic structure-directing side groups. An inorganic precursor with tight binding to the polymer groups is added into a solution containing the polymers. The binding of inorganic species to polymer side groups leads to an increase in inorganic concentration along the polymer chain, which promotes polymerization of inorganic species to form a mesostructured polymer-inorganic composite gel. Upon

quaternary ammonium surfactant with the chemical formula of $\mathrm{C}_{18} \mathrm{H}_{37}-\mathrm{N}^{+}\left(\mathrm{CH}_{3}\right)_{2}-\mathrm{C}_{6} \mathrm{H}_{12}-\mathrm{N}^{+}\left(\mathrm{CH}_{3}\right)_{2}-\mathrm{C}_{6} \mathrm{H}_{12}-$ $\mathrm{N}^{+}\left(\mathrm{CH}_{3}\right)_{2}-\mathrm{C}_{18} \mathrm{H}_{37}$ was synthesized through organic reaction, and it could successfully generate a hexagonallyordered mesoporous framework with crystalline zeolitic micropore walls (Fig. 7) [83]. This material has been a dream material to be synthesized over several decades. The structure-directing role of the $\mathrm{C}_{18-6-6-18}$ surfactant was also clearly demonstrated by $2 \mathrm{D}{ }^{29} \mathrm{Si}\left\{{ }^{1} \mathrm{H}\right\}$ heteronuclear correlation (HETCOR) NMR, which shows the molecular interactions of the surfactant modules to the zeolite framework. From the 2D HETCOR NMR experiment, it was proved that the microporous framework was generated by the hydrophilic head group in the surfactant while the surfactant tails were self-assembled to make a mesoporous framework. Applying this knowledge, a phenyl group was introduced to the hydrophilic head group that can make the hydrophilic head group bulky, and it can produce BEA zeolite with larger micropores $(0.65 \mathrm{~nm}$ in diameter) as nanosponge-type disordered mesoporous structure [83]. The nanosponge-type aggregates consisted of very small zeolite nanocrystals with average size of $2.9 \mathrm{~nm}$, in which the mesopores are present between the nanocrystals. Later, it was also reported that the BEA zeolites with disordered mesopores in a single-crystalline morphology were synthesized by using commercial cationic polymer as a dualfunction template [84]. The size of individual zeolite nanocrystals was systematically controlled in a molecular length scale through the size change of hydrophilic head group. The average thickness of individual zeolite nanocrystals increased from 2.9 to 3.9 and $5.1 \mathrm{~nm}$ as the number of ammonium groups in the hydrophilic head group increased successively from 4 to 6 and 8 . Furthermore, the subsequent solvothermal treatment, the inorganic is transformed to a crystalline framework while tight bonding to polymer is maintained. As the crystal starts to grow, polymer backbones become crowded around surfaces of inorganic crystals. The steric hinderance by the polymer restricts the crystal growths to a thickness of only a few nanometers. Reprinted with permission from Ref. [90]. Copyright 2014 Wiley-VCH Verlag GmbH \& Co. KGaA, Weinheim

mesopore diameters were also tailorable over a wide range of $3.8-21 \mathrm{~nm}$ by adding 1,3,5-trimethylbenzene as a micelle-swelling agent [85].

In addition to the MFI and BEA zeolite reported above, various other zeolite framework structures such as MRE and MTW were synthesized in the form of nanostructures using cationic surfactants containing three or more ammonium ions [73, 82, 83, 86-88]. The hydrophobic tails in the dual-pore-generating surfactant have two important roles according to the literatures reported so far. First, they can be used for making the specific mesoporous structure by assembling themselves to a micellar structure. Second role is that they inhibited further zeolite growth beyond the hydrophilic head group. This role is reminiscent of stabilization of metal nanoparticle surface by organic capping agent. With this similar principle, it is also reported that the various zeolite nanocrystals with framework types of MOR, FAU(X), CHA and MFI were synthesized with cationic surfactants containing two or more ammonium head groups (Fig. 8) [90]. The dual-pore-generating surfactant synthesis strategy can be extended further to zeotype materials such as aluminophosphate material and their zeolite analogues with nano-morphologies [89]. In particular, this synthesis strategy can be applied to metal oxide materials using specially designed random-graft polymer [90].

\section{Advantages of Hierarchically Nanoporous Zeolites as Heterogeneous Catalysts}

The hierarchically nanoporous zeolites have lots of potential for applications to various catalytic reactions that 
Table 2 Temperatureprogrammed desorption of n-hexane, 2-methylpentane and 2,2-dimethylbutane. Reprinted with permission from Ref. [102]. Copyright 2010 Springer

\begin{tabular}{|c|c|c|c|c|c|c|}
\hline \multirow[t]{2}{*}{ Sample } & \multicolumn{2}{|l|}{ n-Hexane } & \multicolumn{2}{|c|}{ 2-Methylpentane } & \multicolumn{2}{|c|}{ 2,2-Dimethylbutane } \\
\hline & Capacity & Peak T & Capacity & Peak T & Capacity & Peak T \\
\hline MFI(300) & 11.72 & 373,439 & 7.35 & 415 & 0 & - \\
\hline MFI(300)S10 & 6.49 & 383,445 & 3.78 & 443 & 0.47 & 455 \\
\hline d30MFI(300) & 8.65 & 388,468 & 1.49 & 488 & 1.00 & 463 \\
\hline
\end{tabular}

are important in the current chemical industries. As compared to the conventional zeolite having only micropores, the main purpose for the development of synthesis strategy for hierarchically nanoporous zeolites is to improve the catalytic performances of conventional zeolites by resolving some limitations such as low molecular diffusion efficiency, quick catalytic deactivation and weak activity to bulky molecules. In this section, the catalytic potentials of hierarchically nanoporous zeolites as the resolution of conventional zeolites will be summarized.

\subsection{Supported Metal Nanoparticles on Zeolites}

Intrinsically, zeolites in the aluminosilicate form have acidic catalytic function that can solely be used as the heterogeneous acid catalyst having both Brönsted and Lewis acid sites with various strengths that are often comparable to the strength of liquid sulfuric acid [91, 92]. In addition to the acid catalytic function, zeolites have been used for supporting metal nanoparticles, which could give bifunctional catalytic function to the zeolite system. Prior to the hierarchical zeolites, metal nanoparticles were supported (or embedded) as the form of the very small nanoclusters inside the micropores of the conventional zeolites [93-95]. The general preparation route includes the introduction of metal cation precursors to the zeolite framework via ion-exchange process through which the metal cations could be exchanged to the negatively charged sites existed on the micropore surface. They are subsequently reduced to make metallic form of nanoclusters at desired reduction temperature under $\mathrm{H}_{2}$ gas condition [96, 97]. Such thermal treatment can make the metal ions to be aggregated as the nanoclusters whose final size can be confined by the size of micropore cavity.

In the case of hierarchical zeolites, metal nanoparticles with various sizes can be supported selectively either on the mesopore surface or inside the micropore cavity. Small metal nanoclusters can be incorporated inside the micropores via the ion-exchange route explained above. However, due to the mesoporous structure, preformed metal nanoparticles with various sizes larger than the micropore can be supported. In this case, hierarchical zeolites were immersed into the organic solvent such as ethanol containing colloidal metal nanoparticles, and the solution was subsequently sonicated for depositing the metal nanoparticles on the mesopore surfaces uniformly [98]. Accordingly, hierarchical zeolites are very useful candidate as the model support for studying the effect of size and shape of metal nanoparticles on the catalytic performances [99].

\subsection{Hydrocarbon Isomerization}

Hydrocarbon isomerization is very important catalytic process that is currently used for upgrading octane value of gasoline by reforming linear hydrocarbons to branchedisomers over metal nanoparticles supported on zeolite catalysts [100, 101]. Various linear hydrocarbons with carbon numbers between $\mathrm{C}_{6}$ to $\mathrm{C}_{12}$ were used as the model reactant. When conventional zeolite was used as the isomerization catalyst, the major problem was quick deactivation of zeolite activity due to the low molecular diffusion efficiency. In particular, large zeolite crystal induced unintended catalytic conversion of reactant and product to make undesirable hydrocarbons such as cracking products. In order to resolve this problem and improve the yield of branched-isomers, there have been many studies with hierarchically nanoporous zeolites.

One representative model hydrocarbon for isomerization study is n-hexane. This can be converted to various products under hydrogenative reforming condition. Various kinds of metal nanoclusters can be incorporated inside the micropores of conventional zeolites. In recent years, hierarchical zeolites have been investigated on this reaction. For example, hierarchical MFI zeolite prepared through post-desilication and subsequent re-crystallization route was tested in this reaction at $327^{\circ} \mathrm{C}$ [102]. The results showed that the hierarchical MFI zeolite produced branched isomers such as 2,2-dimethylbutane having higher octane-value than the parent n-hexane. According to the adsorption analysis, this hierarchically nanoporous MFI zeolite showed small adsorption capacities to n-hexane and 2-methylpentane, but higher adsorption capacity to 2,2dimethylbutane due to the presence of mesopores (Table 2). The mesopores are useful for production of bulkier isomers than smaller products. 
Fig. 9 a Conversion of n-heptane isomerization over hierarchical MFI zeolites according to the variation of reaction temperature, and b their isomer yield data. Reprinted with permission from Ref. [104]. Copyright 2013 Elsevier Inc

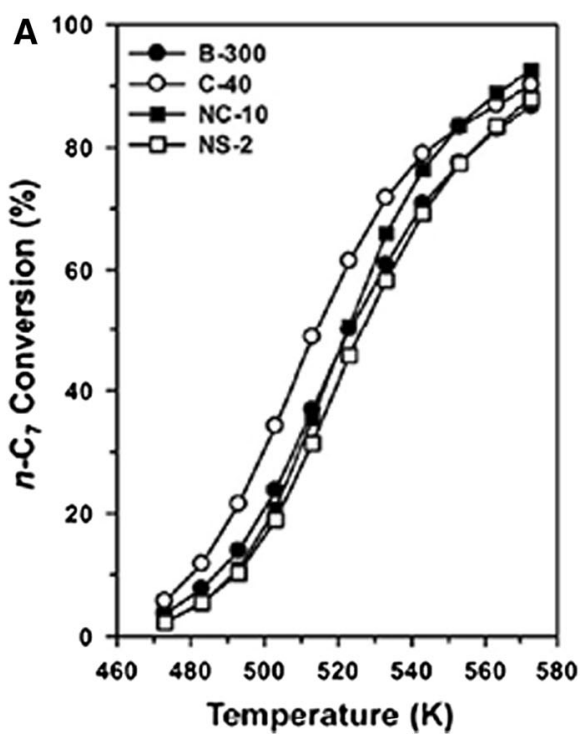

The n-heptane was also used as the model hydrocarbon for isomerization reaction. For example, two different zeolite structures with MTW and BEA having mesoporous structures were tested in n-heptane isomerization [103]. Both zeolites have similar micropore sizes with 12-membered-ring but their connectivity was different. MTW has 1-dimensional connectivity, but BEA has 3-dimensional connectivity. The result revealed that the MTW zeolite exhibited four-times higher activity than conventional MTW zeolite at $260{ }^{\circ} \mathrm{C}$. In addition, the hierarchically nanoporous MTW zeolite yielded $86 \%$ isomers whereas the conventional counterpart produced $72 \%$ isomers. A similar trend was also shown over hierarchically nanoporous BEA zeolite. Such higher catalytic performance over hierarchically nanoporous zeolite can be attributed to the facile diffusion of reactant and product molecules through the mesopores, and the presence of catalytic sites on the mesopore surface that can catalyze the reactants more efficiently than the conventional zeolites possessing micropores only. In more recent year, the nanosheet type of MFI zeolite was also tested for the n-heptane hydroisomerization, where the effect of zeolite crystal thickness on the selectivity to branched-isomers was investigated [104]. The results revealed that the selectivity to the branched isomers became much larger as the thickness of zeolite decreased. It is because that the short diffusion path length allowed branched isomers to escape the catalytic sites before further cracking (Fig. 9).

Isomerization of larger hydrocarbons was also investigated. As the size of model hydrocarbon increased, the reactant diffusion should be affected by the size of zeolite crystals more significantly. A series of MFI zeolite nanosheets with controlled average thickness of 2 and $8 \mathrm{~nm}$ was tested for n-decane isomerization [105], which showed molecular shape-selectivity according to the crystal thickness. Nanosheet-type ITQ-2 zeolite was prepared by dealumination of layered zeolite precursors with FER framework structure, and this material was used for the hydroisomerization of n-hexadecane at $400{ }^{\circ} \mathrm{C}$ in comparison with conventional FER zeolite having only micropores [106]. The results demonstrated that the ITQ-6 exhibited much higher catalytic activity than conventional FER zeolite. In particular, ITQ-6 showed higher isomerization selectivity to cracking, where the isomerization products were more highly branched products than those obtained over conventional FER zeolite. The higher selectivity to isomerization than cracking could be attributed to the short diffusion path length of hierarchical zeolite, which can reduce the number of collision of reactant and branched-isomer products to the catalytic sites. This could prevent the possibility of further cracking as already proved in short hydrocarbon isomerization reactions. For isomerization of hexadecane, hierarchical MFI zeolite in single crystal morphology was also investigated after supporting Pt nanoparticle, which proved enhanced catalytic activity due to the shortened micropore diffusion path length that can dramatically enhance the mass transport within the zeolite crystal [107].

Isomerization of much longer hydrocarbons such as $\mathrm{C}_{18^{-}}$ based fatty acids was investigated over BEA zeolites with controlled acidity and mesoporosity [108]. The isomerization activity increased progressively according to the increase of external surface area on the mesopore wall. In addition to the linear hydrocarbons, aromatic molecular isomerization was also investigated using hierarchical MFI zeolites prepared by post-desilication route [109]. The 
hierarchical MFI zeolite exhibited much higher catalytic activity than parent MFI zeolite without desilication during conversion of o-xylene to p-xylene. Despite the enhanced catalytic activity over hierarchically nanoporous MFI zeolite, the thin zeolite framework showed somewhat less shape-selectivity. The product selectivity to the desired p-xylene decreased somewhat and the undesired m-xylene product was produced more over hierarchical MFI zeolite than parent MFI zeolite with big crystal size. It was demonstrated that such undesirable formation of m-xylene was made over the catalytic sites on the mesopore wall. However, such undesirable formation of $\mathrm{m}$-xylene was alleviated by removing some $\mathrm{Al}$ sites on the external surface with post-acid treatment.

In addition to the practically important catalytic isomerization, reforming of model hydrocarbon such as methylcyclopentane was investigated over hierarchical zeolites supporting Pt metal nanoparticles [98]. In this reaction, two hierarchical zeolites with BEA and MFI framework structures were tested for control of catalytic activity and product selectivity. As compared to the Pt metal nanoparticles supported on MCF-17 mesoporous silica, the Pt/ zeolite catalysts can produce $\mathrm{C}_{6}$-cyclic hydrocarbons such as benzene and cyclohexane most dominantly at $150{ }^{\circ} \mathrm{C}$.

\subsection{Hydrocarbon Cracking}

Catalytic cracking of crude oil is very important chemical process for the large-scale production of commodity compounds [110]. Basically, this process requires breaking of stable $\mathrm{C}-\mathrm{C}$ bond, and hence strong Brönsted acidity of the zeolite is prerequisite. In particular, the FCC and hydrocracking in the presence of $\mathrm{H}_{2}$ gas are extremely important chemical process since huge amounts of heavy hydrocarbon feedstocks are cracked into more valuable fractions. In classical cracking process, zeolite $\mathrm{Y}$ has been used as one of the efficient acid catalysts, showing high catalytic activity [7,111]. However, the conventional Y zeolite with big crystal size has very low mass transport efficiency, which resulted in the quick catalytic deactivation during the cracking reaction. Later, post-dealumination by steaming or acid treatment was employed for making mesoporous structure within the zeolite Y crystal that was named as USY. Although the zeolite framework was somewhat collapsed, the Y zeolite showed very good stability and the dealuminated USY zeolite exhibited high catalytic activity and enhanced lifetime during the cracking reaction.

In addition to the USY zeolite, MFI zeolite has also been used as cracking catalysts. For example, effects of acidity and pore structure of alkali-treated MFI zeolites on the cracking of n-octane were studied [112]. The alkali treatment dissolved silica and alumina, which gave rise to a loss

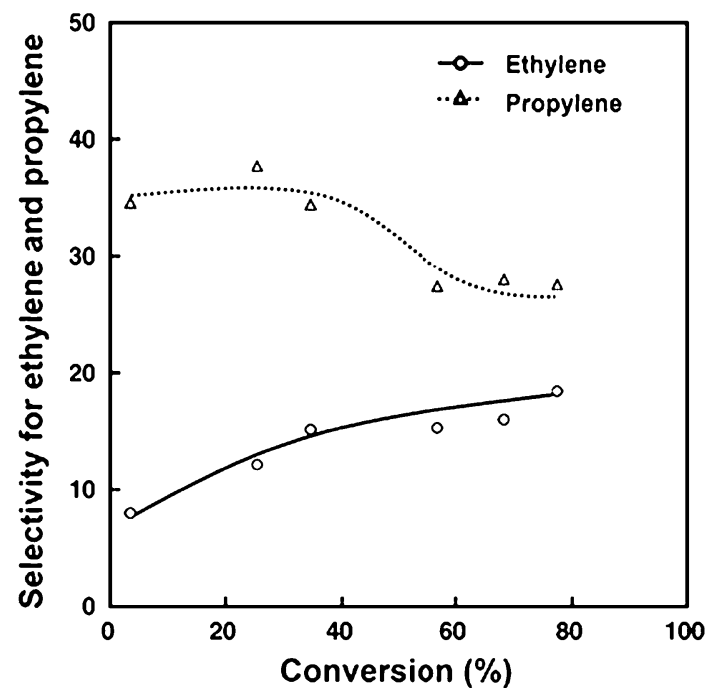

Fig. 10 The variation of the selectivity for ethylene (circle) and propylene (triangle) with conversion over the NaOH-treated MFI zeolites in the catalytic cracking of n-octane. Reprinted with permission from Ref. [112]. Copyright 2005 Elsevier B.V

of strong acidity and formation of mesopores. Accordingly, the alkali-treated hierarchical MFI zeolite produced higher selectivity for propylene, due to the rapid transfer of primary cracking products through thin zeolite framework (Fig. 10). Hierarchical MFI zeolite synthesized with organosilane surfactant as the mesopore SDA was also tested on the cracking of branched polyethylene in comparison with conventional MFI zeolite [113]. The branched polyethylene cannot go into the micropore of MFI zeolite crystal, and hence it can only be cracked at the acid sites existed on the mesopore wall. On the other hand, the hierarchical MFI zeolite exhibited superior catalytic activity, which proves the acidic strength on the mesopore wall is sufficiently high that can catalyze the cracking reaction. In addition, selective dealumination of the external $\mathrm{Al}$ species using bulky acid such as tartaric acid can remove the acid sites on the mesopore wall. Such dealuminated hierarchical MFI zeolite became catalytically inactive for the polyethylene cracking, which clearly indicates that the catalytic reactions of bulky molecules occurred at the acidic sites on the mesopore wall.

In more recent year, MFI zeolite crystals were grown on the surface of a 3D tri-modal glass scaffold [114]. The evaporation induced self-assembly method with P123 triblock-co-polymer and methylcellulose as respective mesopore and macropore directing agents creates ordered arrangement of macropores within MFI zeolite crystal. The glass-MFI zeolite composite showed higher activity than commercial MFI zeolite during $\mathrm{n}$-hexane cracking ( 0.5 vs. $3.5 \mathrm{~mol} / \mathrm{g} / \mathrm{min}$ ) and slightly enhanced propylene selectivity. It is also reported that the hierarchical MFI zeolite 
Fig. 11 a Conversions of n-octane over H-MMZ and $\mathrm{H}-(\mathrm{Z}+\mathrm{M})$ at $400{ }^{\circ} \mathrm{C}$, and b conversions of cumene over $\mathrm{H}-(\mathrm{Z}+\mathrm{M})$ and $\mathrm{H}-\mathrm{MMZ}$ at different temperatures. Reprinted with permission from Ref. [117]. Copyright 2009 Elsevier B.V
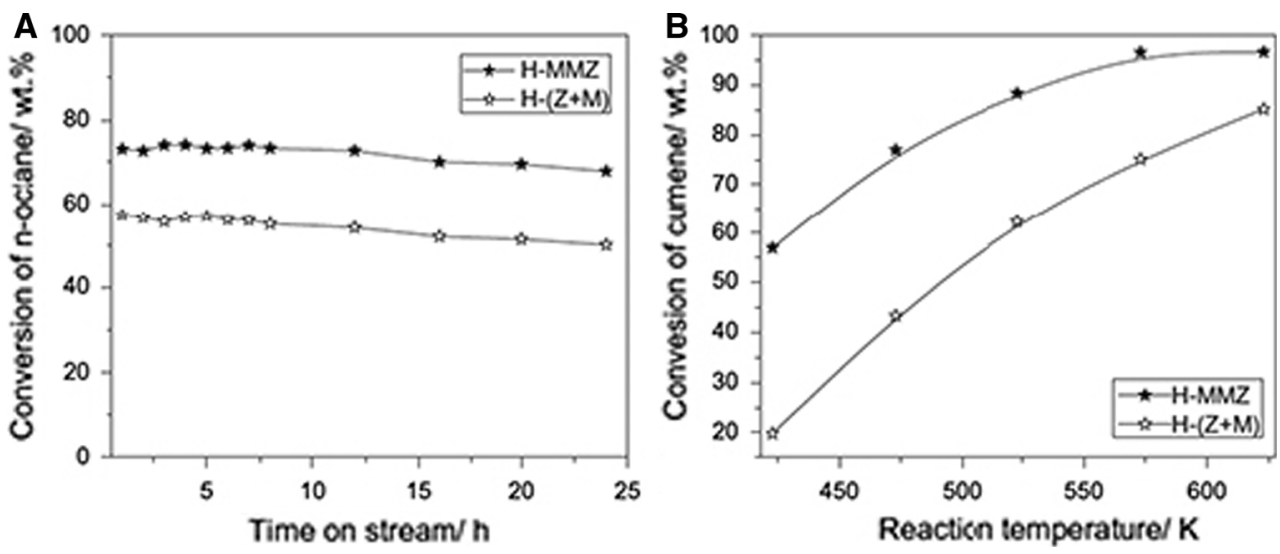

obtained by desilication treatment exhibited markedly improved catalytic performance due to the enhanced diffusion through mesoporous channels [29, 115]. In addition, 20 times higher catalytic activity of desilicated MFI zeolite has been reported in the liquid-phase cracking of highdensity polyethylene. The tri-modal micro-meso-macroporous MFI zeolites could be synthesized through the postsynthetic recrystallization [116], and it showed high activity toward 1,3,5-triisopropylbenzene cracking. Such bulky molecular cracking reaction was done only at the external surface of mesopore and macropore walls.

The MFI zeolite coating grows on the surface of the preformed modernite crystals, with the zeolite composite possessing both $4 \mathrm{~nm}$ mesopores and 50-100 nm macropores from alkaline etching of the modernite core and voids between aggregated MFI crystals. The increased mass transfer and active site accessibility in this hierarchically assembled structure enables it to outperform a physical mixture of the two zeolites for n-octane and cumene cracking (Fig. 11) [117]. In addition, hierarchical MFI zeolite in single crystal morphology was investigated for cracking of hexadecane. The result proved enhanced catalytic activity over hierarchical MFI zeolite as compared to the parent zeolite without mesoporosity, which was attributed to the shortened micropore diffusion path length that can dramatically enhance the mass transport within the zeolite crystal [107].

The cracking activity could be affected not only by the diffusion efficiency, but also by the acid strength of zeolite framework. In usual, the acid strength of the Al sites on the external surface of the mesopore wall is somewhat less strong than the internal acid sites. Nevertheless, it was proved that the acid strength of external Al sites is still stronger than those of Al-incorporated MCM-41-type mesoporous aluminosilicate materials. Accordingly the MFI zeolite nanosheet exhibited faster catalytic conversion in cracking of branched polyethylene as compared to the Al-MCM-41 [73]. In particular, the surface acidity of MFI zeolite nanosheets was later characterized in more detail by using ${ }^{31} \mathrm{P}$ NMR technique after the adsorption of phosphine oxides as the probe molecule [118]. The results proved that there were three types of Brönsted acid sites with different strengths on the external surface of zeolite nanosheet, and four types inside the micropores (Fig. 12). The acidic properties analyzed by ${ }^{31} \mathrm{P}$ NMR were correlated with acid catalytic cracking of bulky hydrocarbon such as decalin that can be catalyzed only at the acid sites on the external surface. The results established a linear correlation between the number of the external strongest acid sites and the catalytic activity in decalin cracking.

\subsection{Alkylation and Acylation Reactions}

Contrary to the cracking reaction mentioned above, alkylation and acylation reactions are bond-making process that can produce value-added fine-chemicals [119, 120]. In usual reaction process, new $\mathrm{C}-\mathrm{C}$ bond could be formed between two substrates, which could make coupled products that are larger than individual reactants. Therefore, though the reactants can enter the micropore of the zeolite, unless the size of micropore is sufficiently large, the bigger product molecules cannot exhaust from the framework. In addition, if the size of transition state coupled by two reactants is larger than the size of micropore, the reaction cannot be achieved. However, the hierarchically nanoporous zeolites have short diffusion path length and large external surface area on the mesopore wall, and hence it can exhibit very efficient mass transport. Accordingly, even if the reaction cannot be placed inside the micropores, the reaction can be arisen over the catalytic sites located on the wider spaces such as mesopore void. This benefit could allow the hierarchical zeolite to be used potentially as good heterogeneous catalyst in alkylation and acylation reactions.

Mesoporous MFI zeolite single-crystal catalyst was shown to be both more active and more selective than 

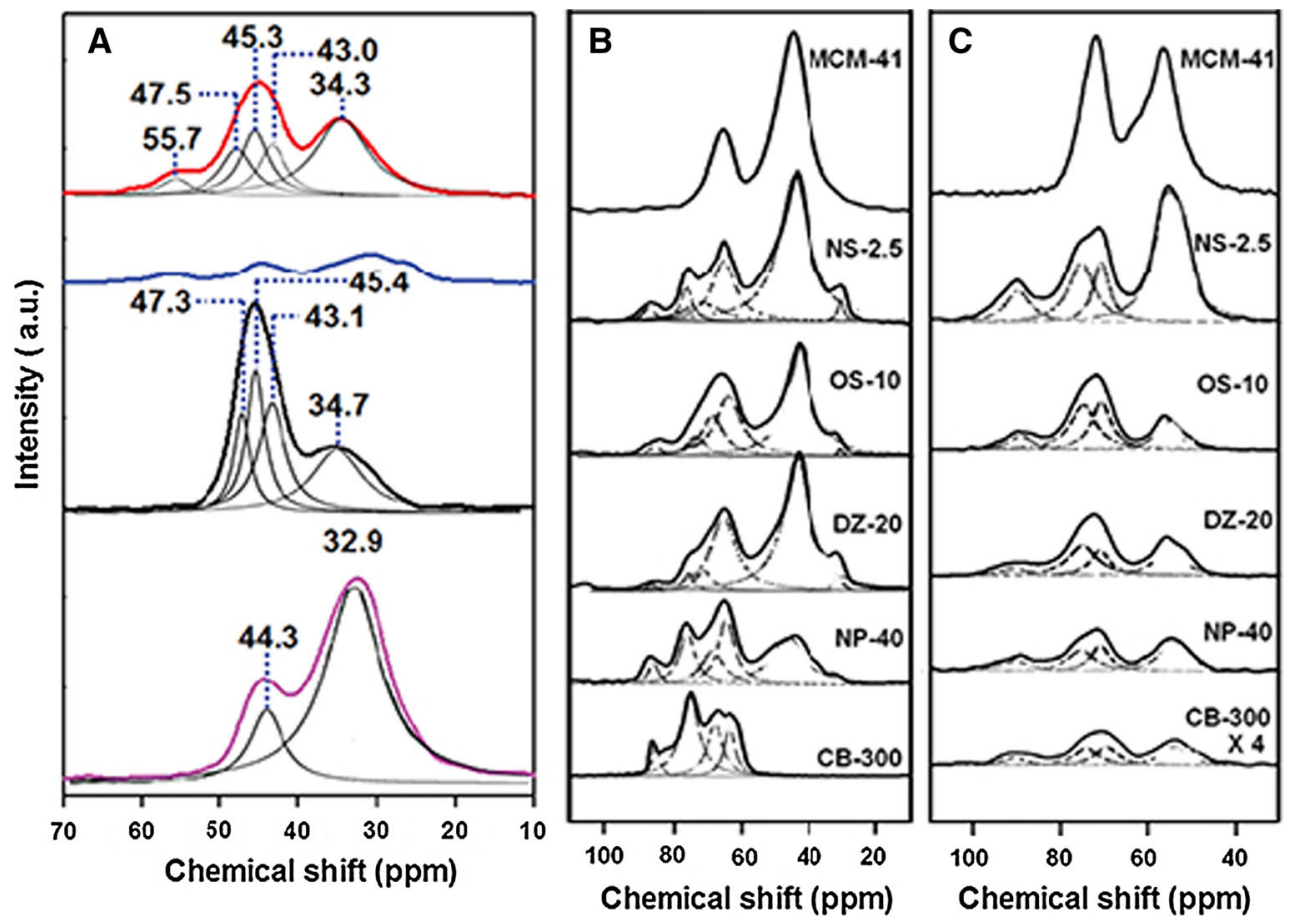

Fig. 12 a ${ }^{31} \mathrm{P}$ MAS NMR spectra of triphenylphosphine oxide adsorbed on Al-MCM-41 ( $\mathrm{Si} / \mathrm{Al}=17$, purple $)$, hexagonally ordered mesoporous zeolite synthesized with the $\mathrm{C}_{18-6-6-18}$ surfactant ( $\mathrm{Si} /$ $\mathrm{Al}=15$, black $)$, bulk BEA zeolite $(\mathrm{Si} / \mathrm{Al}=15$, blue $)$, and nanosponge BEA zeolite synthesized with $\mathrm{N}_{6}$-diphe surfactant ( $\mathrm{Si} /$ $\mathrm{Al}=14$, red $).{ }^{31} \mathrm{P}$ MAS NMR spectra of $\mathbf{B}$ trimethylphosphine

conventional MFI with only micropores during the alkylation of benzene with ethylene [121]. Such superior catalytic performances were explained by improved mass transport through the mesoporous channel inside the zeolite crystal. Nanocrystalline MFI zeolite with intracrystalline mesopores was also synthesized by adding alkyltriethoxysilanes (alkyl = methyl, propyl and octyl) as the mesopore SDA. The resultant hierarchical MFI zeolites exhibited remarkably enhanced catalytic activities in several organic reactions involving large molecules such as benzyl chloride, 7-hydroxy-4-methylcoumarin, or 2-hydroxyacetophenone conversions [122].

A disordered, macroporous MFI zeolite was investigated during the solid-acid catalyzed acylation of anisole with acetic anhydride [123]. The macroporous structure provided the superior diffusion efficiency, which allowed increased anisole conversion more than $80 \%$. This performance is comparable with the conversion levels of 66 and $14 \%$ reported for $90 \mathrm{~nm}$-sized and micron-sized MFI crystals, respectively $[124,125]$. Thus, it can be proven that the thin zeolite crystal is advantageous for improving the catalytic activity. Dual-templating approach using polystyrene bead and TPAOH could generate macroporous MFI zeolite with 300-500 nm macropores and 10-20 nm oxide and c tributylphosphine oxide adsorbed on Al-MCM-41 (MCM-41), nanosheet MFI zeolite (NS-2.5), organosilane-directed MFI zeolite (OS-10), desilicated MFI zeolite (DZ-20), MFI zeolite nanoparticle (NP-40) and conventional MFI zeolite (CB-300). Reprinted with permission from references [83, 118]. Copyrights 2011 from AAAS and 2014 from American Chemical Society

mesopores [126]. This material gave a five-fold increased activity in phenol alkylation with t-butanol as compared to the conventional MFI zeolite.

Sometimes, the thin framework of hierarchical zeolites could be adversely for giving micropore size/shape selectivity. Recently, the effect of MFI zeolite nanosheet morphology on the activity and product selectivity was investigated during toluene alkylation with isopropyl alcohol [127]. The isopropyl alcohol can be coupled with toluene at o-, m- or p-positions. Contrary to the expectation, the high p-selectivity was also obtained even in the use of extremely thin zeolite nanosheets, indicating that the thin zeolite crystal still can exhibit micropore size/shape selectivity.

Dual-pore-generating surfactant-directed synthesis strategy could generate the hexagonally ordered mesoporous zeolite. According to the $\mathrm{NH}_{3}$ TPD and ${ }^{31} \mathrm{P}$ NMR analyses, the external surface of hexagonally ordered mesoporous zeolite has large density of strong acid sites (Fig. 12) [83, 118]. The external acid sites are useful for conversion of various sized aromatic molecules via Friedel-Crafts alkylation or acylation reaction pathways. In addition, it is also proved that the nanosponge-type BEA zeolite exhibited six times higher maximum possible 
catalytic turnovers than conventional BEA zeolite during benzene alkylation reaction [128]. The reason for such enhanced catalytic turnovers was proved by the long lifetime of numerous external acid sites located on the mesopore walls as compared to the internal acid sites inside the micropores. A series of hierarchical BEA, MTW and MRE zeolites was prepared by dual-pore-generating surfactantdirected synthesis strategy and they were tested for isopropylation of benzene. This investigation could reveal the respective contribution of external and internal acid sites on the deactivation phenomenon [87]. The results proved that the external acid sites were contributing more greatly than internal acid sites on the high activity and long catalytic lifetime due to the advantage of slower deactivation than internal acid sites.

\subsection{Oxidation of Olefins}

Partial oxidation of olefin can make epoxides, valuable platform chemicals that can be further converted to finechemicals and polymers. Substitution of $\mathrm{Al}$ atoms in the zeolite framework with transition metals such as $\mathrm{Ti}$ can make the zeolite framework to be used as the oxidation catalysts [129-131]. Among various transition-metal substituted zeolite catalysts, the titanosilicate framework of zeolite crystal has been used as the partial oxidation catalysts for conversion of olefin to epoxides that is simply known as epoxidation reaction. One of the representative titanosilicate zeolites is TS- 1 catalyst having MFI framework structure [131]. The TS-1 catalyst showed outstanding catalytic performances for selective oxidation and epoxidation of various organic compounds with aqueous $\mathrm{H}_{2} \mathrm{O}_{2}$. In this process, the TS- 1 catalyst has only micropores, and hence their applications were limited to the small olefin molecules. Bulky molecular epoxidation for converting larger substrates that cannot enter the micropores of the zeolite framework was not feasible.

The generation of hierarchically nanoporous structure within the titanosilicate zeolite framework could resolve this limitation problem. Hierarchically nanoporous TS-1 zeolite having microporous framework structure of MFI showed high catalytic activity for epoxidation of olefin. Carbon-templated hierarchical TS-1 catalyst was compared to the conventional TS- 1 catalyst in the epoxidation reactions of 1-octene or cyclooctene with $\mathrm{H}_{2} \mathrm{O}_{2}$ at $40{ }^{\circ} \mathrm{C}$ (Fig. 13) [132]. The result showed that the epoxidation of 1-octene is not diffusion-controlled due to the linear molecular structure, which showed quite similar activity over two TS-1 catalysts. However, for the epoxidation of cyclooctene, there was clear improvement in the catalytic activity for the hierarchical TS-1 catalyst [133]. Since the kinetic diameter of cyclooctene is larger than the micropore

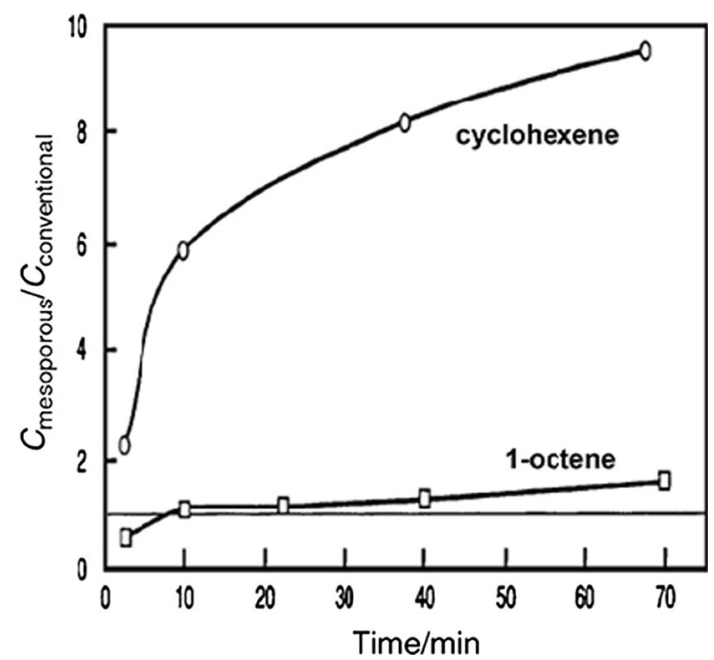

Fig. 13 Ratio of product concentrations [sum of epoxide and secondary products from 1-octene (square) and cyclohexene (circle)] obtained with mesoporous and conventional TS- 1 catalyst as a function of reaction time. The mesoporous TS-1 has a similar activity to the conventional TS-1 for 1-octene epoxidation, whereas the mesoporous TS- 1 shows much higher activity than conventional TS-1 for cyclohexene epoxidation. Reprinted with permission from Ref. [132]. Copyright 2000 Royal Society of Chemistry

size of TS-1, only oxidation catalytic sites on the mesopore wall can catalyze the cyclooctene.

The TS-1 catalyst could also be prepared into the unilamellar form of nanosheet with 2-nm thickness by dualpore-generating surfactant. In the $\mathrm{Na}^{+}$-free synthesis condition, Ti precursor was added to the synthesis solution containing $\mathrm{C}_{22-6-6}$ surfactant in hydroxide form, which could incorporate ca. $1-2 \mathrm{~mol} \% \mathrm{Ti}$ in the siliceous framework with nanosheet morphology. This catalyst exhibited very active and selective catalytic epoxidation for both small olefin such as 1-hexene and bulky cyclic olefins such as cyclohexene and cyclooctene using $\mathrm{H}_{2} \mathrm{O}_{2}$ as an oxidant [134]. The high catalytic activity and selectivity to epoxide indicates that the $\mathrm{Ti}$ atoms were isomorphously substituted in the tetrahedral framework, as coordinated by four-OSi. In addition, multilamellar-type TS-1 zeolite was synthesized with dual-pore-generating surfactant [133]. Due to the wide surface area of mesopore wall, the TS-1 catalyst showed high catalytic activity during the epoxidation of various bulky olefins with various sized oxidants such as t-butyl hydroperoxide, cumene hydroperoxide or aqueous $\mathrm{H}_{2} \mathrm{O}_{2}$.

\subsection{Other Catalytic Reactions}

The framework of the hierarchical zeolites is terminated with high density of silanol groups at the external surfaces, similar to the mesopore walls of MCM-41. These silanol 
Fig. 14 a Catalytic activity and b $\varepsilon$-caprolactam (CL) selectivity as a function of the time-onstream during the gas-phase Beckmann rearrangement of cyclohexanone oxime (CHO) into $\varepsilon$-caprolactam over pure silica MFI catalysts (Reaction conditions: $10 \mathrm{wt} \%$ oxime in ethanol; WHSV, $3 \mathrm{~h}^{-1}$; $\mathrm{T}=350^{\circ} \mathrm{C}$ ). Reprinted with permission from Ref. [137]. Copyright 2011 American Chemical Society

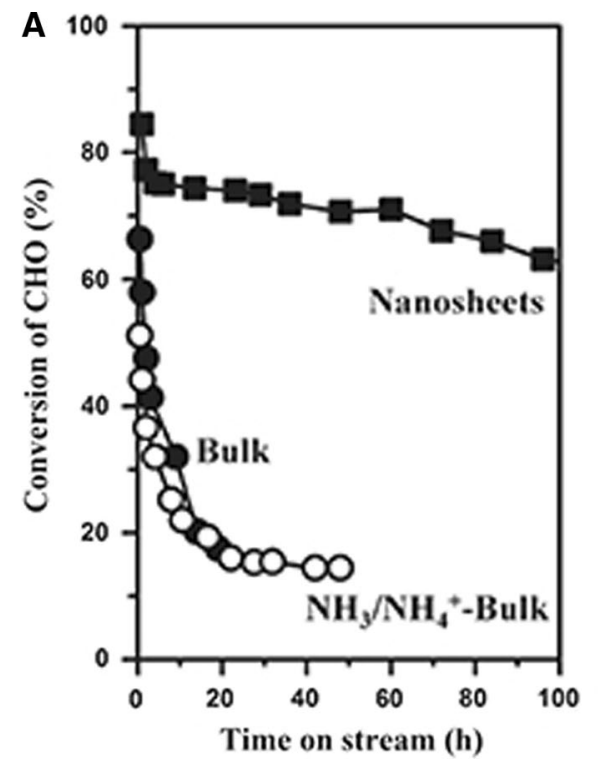

groups can be used for functionalization of organic groups $[135,136]$. However, these silanol groups can also be used as a highly selective catalyst for the gas-phase Beckmann rearrangement of cyclohexanone oxime to $\varepsilon$-caprolactam that is very valuable precursor of Nylon-6 [137]. In usual, pure silica MFI zeolite treated in ammonium solutions before reaction is known to be the active catalyst in the gas-phase reaction. However, this catalyst is not highly selective unless the parent pure silica MFI zeolite was treated with the ammonia before the reaction. In contrast, pure silica form of nanosheet-type MFI zeolite exhibited high catalytic activity and product selectivity, irrespective to the ammonia treatment using $\mathrm{NH}_{3} / \mathrm{NH}_{4}{ }^{+}$solution before the reaction. This performance was attributed to the silanol groups at the external surfaces (010 planes) of the MFI nanosheet, on which the silanols were arranged to form surface pockets that could function like silanol nests. Moreover, the pure silica MFI nanosheet zeolite exhibited 20 times longer catalytic lifetime, as compared to the ammonia treated bulk MFI silica under the same condition (Fig. 14) [137]. Hierarchical ITQ-2 zeolite made by postdealumination of MCM-22 layered zeolite precursor was also reported very active in Beckmann rearrangement of larger size of oxime such as cyclododecanone oxime [138]. In this reaction, the lactam yield at $130{ }^{\circ} \mathrm{C}$ was significantly higher when ITQ-2 was applied as catalysts than when either MCM-41 or conventional BEA zeolite were used.

Fischer-Tropsch (FT) conversion of syngas $\left(\mathrm{CO}+\mathrm{H}_{2}\right)$ to hydrocarbon is at the center of the gas-to-liquid (GTL) processes, which is very powerful catalytic process for production of liquid fuel sources such as gasoline and diesel from syngas [139-141]. Various hierarchical zeolites
Table 3 Catalytic results for the FT conversion reaction on Cosupported catalysts. Reprinted with permission from Ref. [142]. Copyright 2004 Elsevier Inc

\begin{tabular}{|c|c|c|c|c|c|c|c|}
\hline \multirow[t]{2}{*}{ Catalyst } & \multirow{2}{*}{$\begin{array}{l}\mathrm{CO} \\
\text { conv } \\
(\%)\end{array}$} & \multirow{2}{*}{$\begin{array}{l}\text { Reaction } \\
\text { rate }\left(10^{-3}\right. \\
\left.\mathrm{s}^{-1}\right)\end{array}$} & \multirow{2}{*}{$\begin{array}{l}\mathrm{TOF}^{\mathrm{a}} \\
\left(10^{-2}\right. \\
\left.\mathrm{s}^{-1}\right)\end{array}$} & \multicolumn{3}{|c|}{$\begin{array}{l}\text { Product } \\
\text { distribution }(\% \mathrm{C})\end{array}$} & \multirow[t]{2}{*}{$\mathrm{P}^{\mathrm{b}}$} \\
\hline & & & & $\mathrm{C}_{1}$ & $\begin{array}{l}\mathrm{C}_{2-} \\
\mathrm{C}_{4}\end{array}$ & $\mathrm{C}_{5+}$ & \\
\hline Co/ITQ-6 & 37.5 & 5.51 & 4.5 & 10.7 & 11.0 & 78.3 & 0.85 \\
\hline Co/ITQ-2 & 21.9 & 3.30 & 3.4 & 13.2 & 14.2 & 72.6 & 0.83 \\
\hline Co/MCM-41 & 24.3 & 3.80 & 7.2 & 25.6 & 29.7 & 44.7 & 0.76 \\
\hline $\mathrm{Co} / \mathrm{SiO}_{2}$ & 20.2 & 3.01 & 2.6 & 16.6 & 17.9 & 65.5 & 0.81 \\
\hline
\end{tabular}

Reaction conditions: $\mathrm{T}=498 \mathrm{~K}, \mathrm{P}=20 \mathrm{bar}, \mathrm{H}_{2} / \mathrm{CO}=2$, GHSV $=$ $13.5 \mathrm{~L}_{\text {syngas }} /\left(\mathrm{g}_{\text {cat }} \mathrm{h}\right)$

a Turnover Frequencies estimated from the TEM $\mathrm{Co}^{0}$ dispersions and the degree of reduction

b Chain growth probability obtained from the ASF plot in the $\mathrm{C}_{1}-\mathrm{C}_{20}$ hydrocarbon range

supporting various metal nanoparticles such as $\mathrm{Co}, \mathrm{Ru}$ and Fe have been recently investigated for FT conversion [142144]. Co metal nanoparticles were supported on pure-silica delaminated ITQ-2 and ITQ-6 zeolites, among which the Co/ITQ-6 showed the highest activity about 1.5 and 1.8 times higher than that of $\mathrm{Co} / \mathrm{MCM}-41$ and $\mathrm{Co} / \mathrm{SiO} 2$, respectively (Table 3) [142]. It was proved that the high activity of Co/ITQ-6 is ascribed both to a relatively good dispersion and a high reducibility of Co nanoparticles. In more recent years, hierarchical MFI zeolite was used for supporting $\mathrm{Ru}$ metal nanoparticles [143]. This catalyst exhibited very high selectivity $(80 \%)$ to hydrocarbons in the range of gasoline $\left(\mathrm{C}_{5}-\mathrm{C}_{11}\right)$ with a ratio of isoparaffins to n-paraffins of $2.7: 1$. Such favorable formation for the 


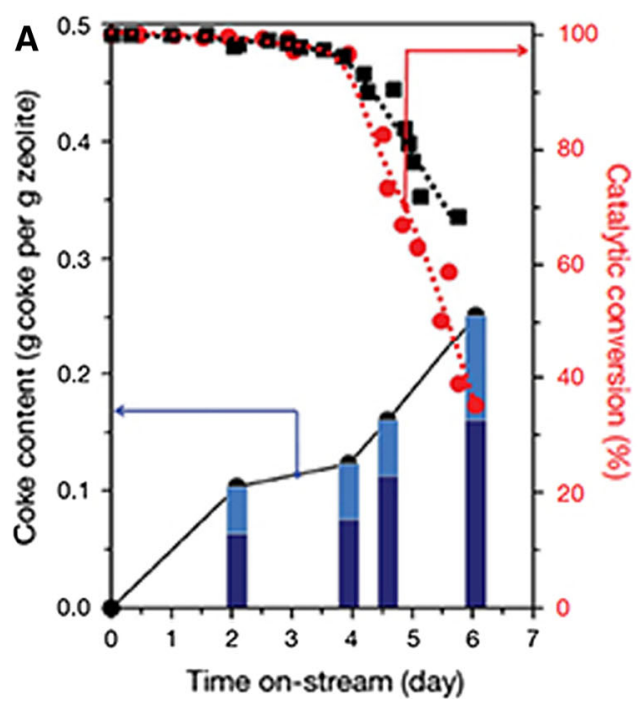

Fig. 15 Coke deposition in MFI zeolite catalysts during MTH conversion. a Conventional MFI and b Unilamellar MFI zeolites. The unilamellar MFI zeolite exhibits a dramatically increased catalytic lifetime compared with its conventional counterpart, which is related to the preferential formation of coke in mesopores (dark

high-octane value gasoline was attributed to the mesoporous structure and the unique acidity of hierarchical MFI zeolite. In addition to the MFI structure, hierarchical BEA zeolite was also tested for FT conversion after supporting Ru metal nanoparticles [144]. Similar to the result obtained over Ru/MFI system, the Ru/BEA zeolite could also produce gasoline-range liquid fuels with high-octane value.

The methanol to hydrocarbon (MTH) conversion is also well-known process for the production of alternative fuel sources, which can be specified into methanol to olefin (MTO) or methanol to gasoline (MTG) depending on the desired products $[145,146]$. In this reaction, the acid catalytic sites on the zeolite framework can catalyze the dehydration reaction of methanol that can be further converted to olefin or gasoline products. This reaction is conversion of small molecule (methanol) to larger hydrocarbon products, which can be affected by molecular diffusion through the zeolite micropores. Accordingly, it was reported that the commercial MFI zeolite with only microporous framework showed very short catalytic lifetime [73]. The initial catalytic activity was deactivated to below $50 \%$ within 1 week of catalytic reaction (Fig. 15). However, the nanosheet MFI zeolite synthesized by dual-pore-generating $\mathrm{C}_{22-6-6}$ surfactant showed much longer catalytic lifetime; more than $50 \%$ of initial catalytic activity was maintained even after 1 month of catalytic reaction. The effect of mesoporosity on the catalytic lifetime during MTH conversion was also investigated, which gave linear correlation between the external surface area and the catalytic lifetime

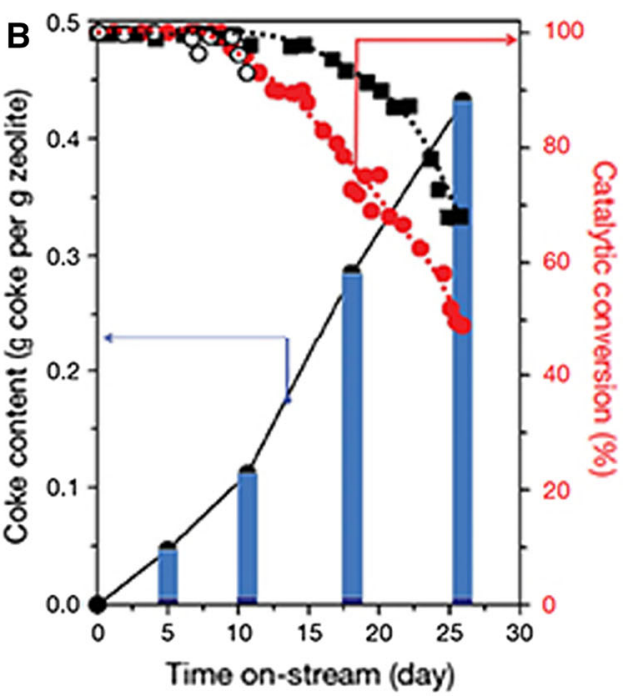

blue bars indicate internal coke content [inside the micropores of the zeolite], and light blue bars indicate external coke content [on the mesopore wall of the zeolite]). Reprinted with permission from Ref. [73]. Copyright 2009 Macmillan Publishers Limited

(Fig. 16) [147]. In other words, as the external surface area of hierarchical zeolite increased, the catalytic lifetime was enhanced progressively.

\section{Summary and Perspectives}

During the past a couple of decades, extensive efforts have been made on the development of hierarchically nanoporous zeolites. Steam-treating dealumination, post-desilication, dual-templating with soft- or hard-templates, and dual-pore-generating surfactant-directing strategies are the novel means for making the hierarchically nanoporous structures in the zeolite architectures over the wide synthesis ranges and zeolite framework types. Such hierarchically nanoporous zeolites have been considered as the solution for unresolved limitations of conventional zeolites having only micropores in heterogeneous catalytic applications. Indeed, it has been proved that the hierarchically nanoporous zeolites can significantly resolve the limitations such as low mass transfer problem, quick deactivation of catalytic activity and low activity to bulky substrates in various chemical reactions.

Benefitting from the cutting-edge synthesis and characterization technologies, the research on the development of new synthesis strategy for the hierarchically nanoporous zeolites almost reached the equilibrium state. However, as compared to the research on the development of new synthesis strategy, some rooms for the researches on the catalytic applications of hierarchically nanoporous zeolites 
Fig. 16 a Catalytic activities of hierarchical zeolites during MTH conversion and b correlation between catalyst lifetime $\left(\mathrm{t}_{1 / 2}\right)$ and external surface areas of hierarchical zeolites. Reprinted with permission from Ref. [147]. Copyright 2010 Elsevier Inc

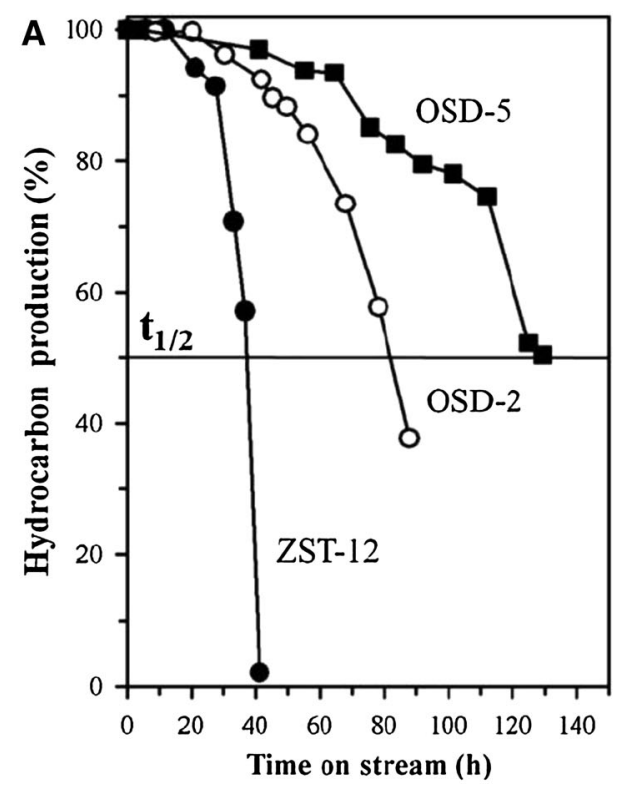

are still remained. In the catalytic point of views, one of the biggest issues in $21^{\text {st }}$ century is making a desired product with high yield and selectivity. Finding the origin of product selectivity control and understanding the reaction mechanism are of great interest for this purpose. Accordingly, it would be very important research issue for deeper understanding on the selectivity control over the surface of zeolites. Through the systematic control of the catalytic surface in a molecular or even an atomic length scale, the varied surface properties of hierarchically nanoporous zeolites will be correlated with the product selectivity. This study will provide deeper understanding on the reaction processes on the surface of zeolite, and give valuable information for further design of hierarchically nanoporous zeolites.

Acknowledgments This work was supported by the Director, Office of Science, Office of Basic Energy Sciences, Division of Chemical Sciences, Geological and Biosciences of the US Department of Energy under contract No. DE-AC-02-05CH11231. The nanoparticle synthesis was funded by Chevron Corporation. We thank Walter Ralston for correcting the proof.

\section{References}

1. Davis ME, Lobo RF (1992) Chem Mater 4:756

2. Corma A (2003) J Catal 216:298

3. Hölderich W, Hesse M, Näumann F (1988) Angew Chem Int Ed Engl 27:226

4. Corma A (1995) Chem Rev 95:559

5. Csicsery SM (1984) Zeolites 4:202

6. Smit B, Maesen TLM (2008) Nature 451:671

7. van Donk S, Janssen AH, Bitter JH, de Jong KP (2003) Catal Rev Sci Eng 45:297

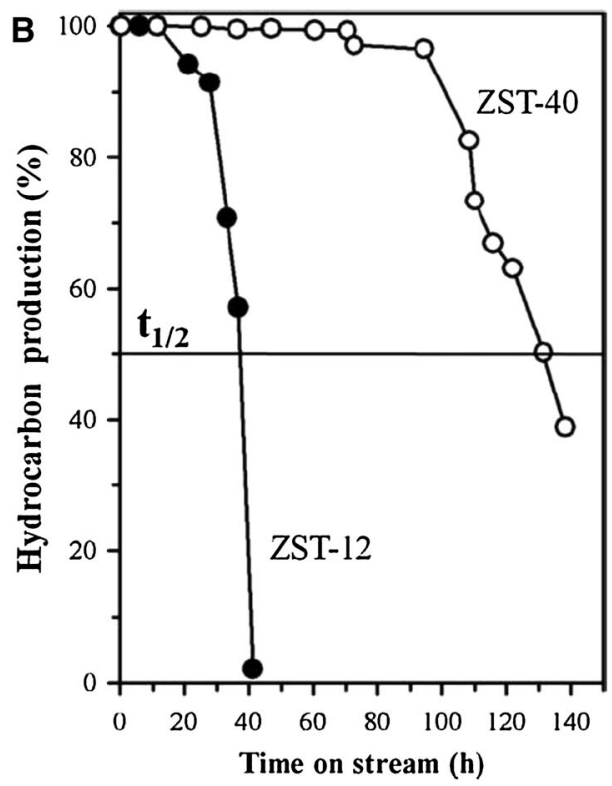

8. Christensen $\mathrm{CH}$, Johannsen K, Törnqvist E, Schmidt I, TopsØe H, Christensen CH (2007) Catal Today 128:117

9. Barrer RM, Denny PJ (1961) J Chem Soc 971

10. Cundy CS, Cox PA (2003) Chem Rev 103:663

11. Baerlocher Ch, Meier WM (1969) Helv Chim Acta 52:1853

12. Wilson ST, Lok BM, Messina CA, Cannon TR, Flanigen EM (1982) J Am Chem Soc 104:1146

13. Groen JC, Moulijn JA, Pérez-Ramírez J (2006) J Mater Chem $16: 2121$

14. Pérez-Ramírez J, Christensen $\mathrm{CH}$, Egeblad K, Christensen $\mathrm{CH}$, Groen JC (2008) Chem Soc Rev 37:2530

15. Möller K, Bein T (2013) Chem Soc Rev 42:3689

16. Beyerlein RA, Choi-Feng C, Hall JB, Huggins BJ, Ray GJ (1997) Top Catal 4:27

17. Sasaki Y, Suzuki T, Takamura Y, Saji A, Saka H (1998) J Catal 178:94

18. Janssen AH, Koster AJ, de Jong KP (2001) Angew Chem Int Ed 40:1102

19. Janssen AH, Koster AJ, de Jong KP (2002) J Phys Chem B 106:11905

20. Le Van Mao R, Vo NTC, Sjiariel B, Lee L, Denes G (1992) J Mater Chem 2:595

21. Triantafillidis CS, Vlessidis AG, Evmiridis NP (2000) Ind Eng Chem Res 39:307

22. Beyer HK, Belenyakaja I (1980) Stud Surf Sci Catal 5:203

23. Scherzer J (1984) ACS Symp Ser 248:157

24. Goyvaerts D, Martens JA, Grobet PJ, Jacobs PA (1991) Stud Surf Sci Catal 63:381

25. Chal R, Gérardin C, Bulut M, van Donk S (2011) ChemCatChem 3:67

26. Groen JC, Bach T, Ziese U, Paulaime-van Donk AM, de Jong KP, Moulijn JA, Pérez-Ramírez J (2005) J Am Chem Soc 127:10792

27. Groen JC, Zhu W, Brouwer S, Huynink SJ, Kapteijn F, Moulijn JA, Pérez-Ramírez J (2007) J Am Chem Soc 129:355

28. Dessau RM, Valyocsik EW, Goeke NH (1992) Zeolites 12:776

29. Ogura M, Shinomiya S, Tateno J, Nara Y, Numura M, Kikuchi E, Matsukata M (2001) Appl Catal A Gen 219:33

30. Groen JC, Jansen JC, Moulijn JA, Pérez-Ramírez J (2004) J Phys Chem B 108:13062 
31. de Jong KP, Zečević J, Friedrich H, de Jongh PE, Bulut M, van Donk S, Kenmogne R, Finiels A, Hulea V, Fajula F (2010) Angew Chem Int Ed 49:10074

32. Chal R, Cacciaguerra R, van Donk S, Géradin C (2010) Chem Commun (46):7840

33. Egeblad K, Christensen CH, Kustova M, Christensen CH (2008) Chem Mater 20:946

34. Lu AH, Schüth F (2006) Adv Mater 18:1793

35. Wan Y, Zhao D (2007) Chem Rev 107:2821

36. Jacobsen CJH, Madsen C, Houzvicka J, Schmidt I, Carlsson A (2000) J Am Chem Soc 122:7116

37. Schmidt I, Boisen A, Gustavsson E, Stahl K, Pehrson S, Dahl S, Carlsson A, Jacobsen CJH (2001) Chem Mater 13:4416

38. Boisen A, Schmidt I, Carlsson A, Dahl S, Brorson M, Jacobsen CJH (2003) Chem Commun (8):958

39. Janssen AH, Schmidt I, Jacobsen CJH, Koster AJ, de Jong KP (2003) Microporous Mesoporous Mater 65:59

40. Zhu K, Egeblad K, Christensen CH (2007) Eur J Inorg Chem 2007:3955

41. Kustova M, Egeblad K, Zhu K, Christensen CH (2007) Chem Mater 19:2915

42. Tao YS, Kanoh H, Kaneko K (2003) J Am Chem Soc 125:6044

43. Pekala RW, Alviso CT, Kong FM, Hulsey SS (1992) J NonCryst Solids 145:90

44. Bekyarova E, Kaneko K (2000) Adv Mater 12:1625

45. Hanzawa Y, Kaneko K, Yoshizawa N, Pekala RW, Dresselhaus MS (1998) Adsorption 4:187

46. Hanzawa Y, Hatori H, Yoshizawa N, Yamada Y (2002) Carbon 40:575

47. Tao Y, Kanoha H, Hanzawa Y, Kaneko K (2004) Colloids Surf A $241: 75$

48. Kustova M, Hasselriis P, Christensen CH (2004) Catal Lett 96:205

49. Wei X, Smirniotis PG (2006) Microporous Mesoporous Mater 89:170

50. Pavlačková Z, Košová G, Silková N, Zukal A, Čejka J (2006) Stud Surf Sci Catal 162:905

51. Egeblad K, Kustova M, Klitgaard SK, Zhu K, Christensen CH (2007) Microporous Mesoporous Mater 101:214

52. Sakthivel A, Huang S, Chen W, Lan Z, Chen K, Kim T, Ryoo R, Chiang AST, Liu S (2004) Chem Mater 16:3168

53. Yang Z, Xia Y, Mokaya R (2004) Adv Mater 16:727

54. Ryoo R, Joo SH, Jun S (1999) J Phys Chem B 103:7743

55. Ryoo R, Joo SH, Kruk M, Jaroniec M (2001) Adv Mater 13:677

56. Fang Y, Hu H (2006) J Am Chem Soc 128:10636

57. Fan W, Snyder MA, Kumar S, Lee PS, Yoo WC, McCormick AV, Penn RL, Stein A, Tsapatsis M (2008) Nature Mater 7:984

58. Holland BT, Abrams L, Stein A (1999) J Am Chem Soc 121:4308

59. Cho HS, Ryoo R (2012) Microporous Mesoporous Mater 151:107

60. Karlsson A, Stöcker M, Schmidt R (1999) Microporous Mesoporous Mater 27:181

61. Liu Y, Zhang WZ, Pinnavaia TJ (2000) J Am Chem Soc 122:8791

62. Liu Y, Zhang WZ, Pinnavaia TJ (2001) Angew Chem Int Ed 40:1255

63. Zhang Z, Han Y, Xiao FS, Qiu S, Zhu L, Wang R, Yu Y, Zhang Z, Zou B, Wang Y, Sun H, Zhao D, Wei Y (2001) J Am Chem Soc 123:5014

64. Liu Y, Pinnavaia TJ (2002) Chem Mater 14:3

65. Naik SP, Chiang AST, Thompson RW (2003) J Phys Chem B 107:7006

66. Choi M, Cho HS, Srivastava R, Venkatesan C, Choi DH, Ryoo R (2006) Nature Mater 5:718

67. Chmelka BF (2006) Nature Mater 5:681
68. Hüttinger KJ, Jung MF (1989) Chem Ing Tech 61:258

69. Choi M, Srivastava R, Ryoo R (2006) Chem Commun (42):4380

70. Sun Q, Wang N, Xi D, Yang M, Yu J (2014) Chem Commun 50:6502

71. Shangbhag GV, Choi M, Kim J, Ryoo R (2009) J Catal 264:88

72. Kresge CT, Leonowicz ME, Roth WJ, Vartuli JC, Beck JS (1992) Nature 359:710

73. Choi M, Na K, Kim J, Sakamoto Y, Terasaki O, Ryoo R (2009) Nature 461:246

74. Corma A (2009) Nature 461:182

75. Roth WJ, Nachtigall P, Morris RE, Čejka J (2014) Chem Rev 114:4807

76. Na K, Choi M, Park W, Sakamoto Y, Terasaki O, Ryoo R (2010) J Am Chem Soc 132:4169

77. Maheshwari S, Jordan E, Kumar S, Bates FS, Penn RL, Shantz DF, Tsapatsis M (2008) J Am Chem Soc 130:1507

78. Tsapatsis M, Maheshwari S (2008) Angew Chem Int Ed 47:4262

79. Roth WJ, Čejka J (2011) Catal Sci Technol 1:43

80. Zhang X, Liu D, Xu D, Asahina S, Cychosz KA, Agrawal KV, Wahedi YA, Bhan A, Hashimi SA, Terasaki O, Thommes M, Tsapatsis M (2012) Science 336:1684

81. Xu D, Ma Y, Jing Z, Han L, Singh B, Feng J, Shen X, Cao F, Oleynikov P, Sun H, Terasaki O, Che S (2014) Nature Comm. doi:10.1038/ncomms5262

82. Park W, Yu D, Na K, Jelfs KE, Slater B, Sakamoto Y, Ryoo R (2011) Chem Mater 23:5131

83. Na K, Jo C, Kim J, Cho K, Jung J, Seo Y, Messinger RJ, Chmelka BF, Ryoo R (2011) Science 333:328

84. Zho J, Zhu Y, Zhu L, Rigutto M, van der Made A, Yang C, Pan S, Wang L, Zhu L, Jin Y, Sun Q, Wu Q, Meng X, Zhang D, Han Y, Li J, Chu Y, Zheng A, Qiu S, Zheng X, Xiao FS (2014) J Am Chem Soc 136:2503

85. Jo C, Jung J, Ryoo R (2014) Microporous Mesoporous Mater 194:83

86. Jung J, Jo C, Cho K, Ryoo R (2012) J Mater Chem 22:4637

87. Kim W, Kim JC, Kim J, Seo Y, Ryoo R (2013) ACS Catal 3:192

88. Jo C, Jung J, Shin HS, Kim J, Ryoo R (2013) Angew Chem Int Ed 52:10014

89. Seo Y, Lee S, Jo C, Ryoo R (2013) J Am Chem Soc 135:8806

90. Jo C, Seo Y, Cho K, Kim J, Shin HS, Lee M, Kim JC, Kim SO, Lee JY, Ihee H, Ryoo R (2014) Angew Chem Int Ed 53:5117

91. Barthomeuf D (1979) J Phys Chem 83:249

92. Haw JF (2002) Phys Chem Chem Phys 4:5431

93. Stucky GD, Zheng N (2006) J Am Chem Soc 128:14278

94. Astruc D (2008) Nanoparticles and Catalysis. Wiley, Weinheim 95. Na K, Zhang Q, Somorjai GA (2014) J Cluster Sci 25:83

96. Larsen G, Haller GL (1989) Catal Lett 3:103

97. Samant MG, Boudart M (1991) J Phys Chem 95:4070

98. Na K, Musselwhite N, Cai X, Alayoglu S, Somorjai GA (2014) J Phys Chem A 118:8446

99. Prieto G, Martínez A, Concepción P, Moreno-Tost R (2009) J Catal 266:129

100. Corma A (1993) Catal Lett 22:33

101. Martens JA, Verboekend D, Thomas K, Vanbutsele G, Gilson JP, Pérez-Ramírez J (2013) ChemSusChem 6:421

102. Chao PH, Tsai ST, Chang SL, Wang I, Tsai TC (2010) Top Catal 53:231

103. Moushey DL, Smirniotis PG (2009) Catal Lett 129:20

104. Kim J, Kim W, Seo Y, Kim JC, Ryoo R (2013) J Catal 301:187

105. Verheyen E, Jo C, Kurttepeli M, Vanbutsele G, Gobechiya E, Korányi TI, Bals S, van Tendeloo G, Ryoo R, Kirschhock CEA, Martens JA (2013) J Catal 300:70

106. Chica A, Diaz U, Fornés V, Corma A (2008) Catal Today 147:179

107. Christensen CH, Schmidt I, Christensen CH (2004) Catal Commun 5:543 
108. Zhang S, Zhang ZC (2007) Catal Lett 115:114

109. Fernandez C, Stan I, Gilson JP, Thomas K, Vicente A, Bonilla A, Pérez-Ramírez J (2010) Chem Eur J 16:6224

110. Vermeiren W, Gilson JP (2009) Top Catal 52:1131

111. Rabo JA, Schoonover MW (2001) Appl Catal A 222:261

112. Jung JS, Park JW, Seo G (2005) Appl Catal A Gen 288:149

113. Shetti VN, Kim J, Srivastava R, Choi M, Ryoo R (2008) J Catal 254:296

114. Louis B, Ocampo F, Yun HS, Tessonnier JP, Pereira MM (2010) Chem Eng J 161:397

115. Su L, Liu L, Zhuang J, Wang H, Li Y, Shen W, Xu Y, Bao X (2003) Catal Lett 91:155

116. Yang XY, Tian G, Chen LH, Li Y, Rooke JC, Wei YX, Liu ZM, Deng Z, van Tendeloo G, Su BL (2011) Chem Eur J 17:14987

117. Zheng J, Zhang X, Zhang Y, Ma J, Li R (2009) Microporous Mesoporous Mater 122:264

118. Seo Y, Cho K, Jung Y, Ryoo R (2013) ACS Catal 3:713

119. Bandini M, Melloni A, Umani-Ronchi A (2004) Angew Chem Int Ed 43:550

120. Bejblová M, Procházková D, Čejka J (2009) ChemSusChem 2:486

121. Christensen $\mathrm{CH}$, Johannsen K, Schmidt I, Christensen $\mathrm{CH}$ (2003) J Am Chem Soc 125:13370

122. Srivastava R, Iwasa N, Fujita SI, Arai M (2008) Chem Eur J 14:9507

123. Padmanabhan A, Selvin R, Hsu HL, Xiao LW (2010) Chem Eng Technol 33:998

124. Selvin R, Hsu HL, Her TM (2008) Catal Commun 10:169

125. Freese U, Heinrich F, Roessner F (1999) Catal Today 49:237

126. Xu L, Wu S, Guan J, Wang H, Ma Y, Song K, Xu H, Xing H, Xu C, Wang Z, Kan Q (2008) Catal Commun 9:1272

127. Jo C, Ryoo R, Žilková N, Vitvarová D, Čejka J (2013) Catal Sci Tech 3:2119
128. Kim JC, Cho K, Ryoo R (2014) Appl Catal A Gen 470:420

129. Camblor MA, Corma A, Martínez A, Pérez-Pariente J (1992) J Chem Soc Chem Commun (8):589

130. Corma A, Navarro MT, Pérez-Pariente J (1994) J Chem Soc Chem Commun (2):147

131. Taramasso M, Perego G, Notari B (1983) US Patent 4410501

132. Schmidt I, Krogh A, Wienberg K, Carlsson A, Brorson M, Jacobsen CJH (2000) Chem Commun (21):2157

133. Wang J, Xu L, Zhang K, Peng H, Wu H, Jiang JG, Liu Y, Wu P (2012) J Catal 288:16

134. Na K, Jo C, Kim J, Ahn WS, Ryoo R (2011) ACS Catal 1:901

135. Huh S, Wiench JW, Yoo JC, Pruski M, Lin VSY (2003) Chem Mater 15:4247

136. Lee DH, Choi M, Yu BW, Ryoo R (2008) Chem Commun (1):74

137. Kim J, Park W, Ryoo R (2011) ACS Catal 1:337

138. Botella P, Corma A, Iborra S, Monton R, Rodriguez I, Costa V (2007) J Catal 250:161

139. Dry ME (1990) Catal Today 6:183

140. Khodakov AY, Chu W, Fongarland P (2007) Chem Rev 107:1692

141. Zhang Q, Kang J, Wang Y (2010) ChemCatChem 2:1030

142. Concepción P, López C, Martínez A, Puntes VF (2004) J Catal 228:321

143. Kang J, Cheng K, Zhang L, Zhang Q, Ding J, Hua W, Lou Y, Zhai Q, Wang Y (2011) Angew Chem Int Ed 50:5200

144. Cheng K, Kang J, Huang S, You Z, Zhang Q, Ding J, Hua W, Lou Y, Deng W, Wang Y (2012) ACS Catal 2:441

145. Stöcker M (1999) Microporous Mesoporous Mater 29:3

146. Haw JF, Song WG, Marcus DM, Nicholas JB (2003) Acc Chem Res 36:317

147. Kim J, Choi M, Ryoo R (2010) J Catal 269:219 